\title{
First impression biases in the performing arts: taste-based discrimination and the value of blind auditioning
}

\author{
Jasmin Droege $^{1}$
}

Received: 23 October 2020 / Accepted: 28 May 2021 / Published online: 8 September 2021

(C) The Author(s) 2021

\begin{abstract}
I develop a game-theoretic framework to study the repercussions of an evaluator's bias against a specific group of applicants. The evaluator decides upfront between holding an informed or a blind audition. In the latter, the evaluator learns neither the applicant's ability nor the gender. I show that, above a threshold bias, the evaluator prefers a blind audition to provide high effort incentives exclusively for highability applicants. Consequently, committing to no information can be beneficial for the evaluator. I also show that a highly biased evaluator's preferences align with those of a highly able female. I extend the framework to performance uncertainty and gender-blind CVs and compare blind auditions to affirmative action. The framework is relevant for auditory-based applications: my results can explain why blind auditions have increased the probability of a female orchestra musician being hired via taste-based discrimination and challenge explanations grounded in statistical discrimination.
\end{abstract}

Keywords First impression · Bias · Blind audition · Taste-based discrimination · Performance uncertainty

JEL Classification C70 $\cdot$ D81 $\cdot$ D86 $\cdot$ D91 $\cdot$ J16 $\cdot$ J71

\section{Introduction}

"I've been in auditions without screens, and I can assure you that I was prejudiced. I began to listen with my eyes, and there is no way that your eyes don't affect your judgment. The only true way to listen is with your ears and your heart."

-Julie Landsman in Gladwell, Blink: The Power of Thinking Without Thinking

Jasmin Droege

jasmin.droege@nuffield.ox.ac.uk

1 Nuffield College and Department of Economics, University of Oxford, Oxford, UK 
Auditions are common practice in the performing arts to hire the best candidate. The evaluator, who makes the hiring decision, chooses upfront between two audition forms. If informed, the evaluator requires applicants to submit information prior to the audition. This often takes the form of a $\mathrm{CV}$ which contains valuable information about ability. One proxy for ability is the school an applicant went to, such as Juilliard, which leads the evaluator's belief about her ability to increase. A CV, however, also contains irrelevant information about gender or race. ${ }^{1}$ This may result in first impression biases which discount more relevant information obtained at a later stage (Thorngate et al. 2010). If blind, the evaluator receives no information and, because the evaluator cannot see the applicant during her performance, the hiring decision is based purely on sound. Given the audition form, the applicant decides whether to participate and how much effort to invest in preparing a performance. Importantly, this sequential decision-making of the potentially biased evaluator and the applicant allows the audition form to affect effort incentives.

In this paper, I analyse the repercussions of the evaluator's bias against a specific group of applicants. I examine whether, and under which conditions, it can be rational for the evaluator to commit to ignore supplementary information about an applicant to avoid misleading first impressions. I ask whether the move to a blind audition can lead to better candidates being hired; in essence, can a blind audition provide better effort incentives exclusively for highly able applicants?

My main contribution lies in providing a theory for Goldin and Rouse's (2000) finding that the use of blind auditions in US orchestras has lead to a severalfold increase in the probability that a female will be hired. Furthermore, I address the two polarised views on the use of blind auditions to hire the best candidate. Proponents argue that blind auditions have helped evaluators avoid misleading first impressions (Gladwell 2005). ${ }^{2}$ In fact, blind auditions have often been marketed as a fairer form of audition and equal opportunity policy (Karl Schiebler in The Economist 1996). ${ }^{3}$ Opponents fear that, while avoiding bias, the evaluator loses valuable information that can screen applicants by ability (Blasko in Makoff-Clark 2019). Consequently, top talent may be lost in an increasingly large applicant pool and standards of fairness may even deteriorate (Holland 1981). My second contribution is to show that the two polarised views are not mutually exclusive. I argue that a blind audition comes with a fundamental trade-off: it grants impartiality to the evaluator but may prohibit the screening of applicants by ability.

\footnotetext{
${ }^{1}$ In countries like France, Belgium or Germany, it is common to include a photograph that likely reveals gender or race. Even in countries like the UK where it is advised against the inclusion of a photograph or personal details like birthplace due to equal opportunity legislation, the first and last name may reveal gender or race; see Bertrand and Mullainathan (2004) for an experiment that randomly assigns AfricanAmerican- or White-sounding names to CVs.

${ }^{2}$ Gladwell (2005) bases his argument on the prejudices that women have encountered in the past when auditioning for orchestra positions. Two examples are not possessing the physical strength for instruments traditionally considered "male", or an inferior attitude and resilience compared to males.

${ }^{3}$ John de Mol, the creator of the singing competition "The Voice", for example, argues that the TV show's blind auditions allow the judges to focus on quality alone and identify genuine singing talent (Universal Music Group 2011).
} 
I develop a game-theoretic framework in which the evaluator is biased against females and his bias is common knowledge. The evaluator commits to a blind or an informed audition given an exogenously determined wage. He always fills the position with an applicant or a random outside option. His revenue is determined by performance quality and ability, whereas the applicant cares only about being hired. In the benchmark model, effort maps one-to-one into performance quality. In an extension, I allow for moral hazard by considering a setting where low effort can result in low or high performance quality. I focus on a gender bias and frequently use the context of an orchestra to build intuition. This focus also emphasises that artistic auditions are a key application as the underrepresentation of women in virtually all the arts provides evidence for some degree of discrimination (Hellmanzik 2020). ${ }^{4}$ However, my framework pertains to a broader range of contexts in which the evaluator requires the applicant to prepare a project for review and possibly submit additional information susceptible to bias, before deciding upon acceptance. In particular, technology companies like 'GapJumpers' (Cain Miller 2016) or 'Applied' (Glazebrook 2019) allow firms to implement blind hiring through software that withholds personal information. ${ }^{5}$ Academia may be another application if blind auditioning can help to address the lower success rates of female applicants for funding schemes such as ERC grants (Vernos 2013). ${ }^{6}$

My main result is that there exists a threshold bias above which the evaluator prefers a blind audition to provide targeted effort incentives: high effort incentives for highly able applicants while low-ability applicants do not participate. Consequently, committing to no information can be beneficial for the evaluator. Moreover, above the threshold bias, equal opportunity and targeted effort incentives are complementary objectives: there is no trade-off between implementing blind auditions as a policy to counteract first impression biases and efficiency due to adverse effects on targeted effort provision. If anything, the implementation of equal opportunity is effort-enhancing for high-ability applicants above this threshold. Perhaps surprisingly, the preferences of a highly biased evaluator align with the preferences of high-ability females: a blind audition provides targeted effort incentives and, as a side effect, plays out in favour of high-ability females, as they prefer to conceal their gender. My model sheds light on the forces underlying the empirical findings on the use of blind auditions and shows that the gains from being able to conceal one's gender need not be uniform. For a low bias, the gains from moving to a blind audition accrue to low-ability females. If the bias is high, the gains accrue to high-ability females.

I show in an extension that a blind audition cannot provide targeted effort incentives if performance uncertainty exceeds some threshold. Consequently, for a highly

\footnotetext{
4 See Chapter 5 in Hellmanzik (2020) for an excellent case study of discrimination in artistic labour markets and a discussion of the classic work by Goldin and Rouse (2000).

5 With a commonly known gender bias, such intermediaries may also serve as a commitment device to blind hiring.

6 The act of withholding applicants' names may already have a significant effect; see, for example, Mullainathan's (2004) experiment. For an example of name-blind hiring, see the UK Civil Cervice (Manzoni 2015).
} 
biased evaluator, a blind audition is no longer guaranteed to be more profitable than an informed audition. Moreover, there is the sizeable risk of market failure: for certain parameter combinations, neither a blind nor an informed audition is profitable and the evaluator might not want to hold an audition at all. Interventions that ensure the applicant pool to be of sufficiently high ability under performance uncertainty guarantee the profitability of a blind audition when the evaluator is highly biased and avoid market failure. Finally, I show that a policy maker may want to allow a moderately biased evaluator to request a gender-blind CV prior to a blind audition.

\subsection{Related literature}

My paper relates to several strands of the literature. I draw upon the literature on cognitive biases: I argue that the evaluator in an informed audition is likely subject to different types of biases which may be summarised in a reduced-form parameter. One potential driver is intergroup bias: the evaluator may judge members of his own group more favourably (Hewstone et al. 2002; Anwar 2012; Bagues and Perez-Villadoniga 2012). In orchestras, gender associations with instruments may drive bias (Abeles 2009; Stronsick et al. 2018; Sergeant and Himonides 2019). A third potential driver is due to interaction effects of gender and race: in experimental judging sessions, videotaped males tend to score lowest among black performers; females lowest among whites (Elliott 1995). Extraneous factors warrant the modelling of bias in performance evaluation. This can be as subtle as the strength of the applicant's handshake at the audition if this opening ritual influences the evaluator's belief about her character strength. ${ }^{7}$ Other examples are attractiveness or accent (Purkiss et al. 2006). ${ }^{8}$

I draw upon contract theory by assuming verifiable disclosure (Milgrom 1981; Grossman 1981): in an informed audition, the applicant cannot misrepresent her gender nor ability on her CV. Conversely, the evaluator cannot commit to cherrypick relevant information. Effort incentives are, therefore, influenced by the evaluator's bias via his hiring rule. This feature is similar to implicit incentives arising in a dynamic setting (Meyer and Vickers 1997). The evaluator has a menu of audition forms available to hire the best candidate and, given his commonly known bias, needs to choose the optimal form (Laffont and Tirole 1986). ${ }^{9}$ Moreover, the blind audition is akin to a signalling model à la Spence (1973) as the applicant's effort

\footnotetext{
${ }^{7}$ In particular, "[b]ecause men tend to have greater upper body strength than do women, a male's handshake is likely to be firmer than a female's handshake". As a result, "if the [evaluator] shakes a woman's hand, it is more likely the shake will fail the [evaluator]'s character test", leading him to discount more relevant information obtained from the female's subsequent performance (Thorngate et al. 2010, p. 51).

${ }^{8}$ There is evidence for a vision heuristic: evaluators consistently report to value sound as central in performance. However, they select different winners if they have visual information about the applicant (Tsay 2013).

${ }^{9}$ In Laffont and Tirole (1986), the evaluator would be the agent. The principal would be a regulator in charge of what audition forms are available to the evaluator; for example, the admission of gender-blind CVs (Section 9).
} 
decision may be informative about the ability dimension of her type while gender cannot be signalled.

My paper builds on the literature in the economics of discrimination. In models of statistical discrimination (Phelps 1972; Arrow 1973), the evaluator has to believe that women are, on average, less productive than men to use gender in the hiring decision as a proxy for unobservable ability. In taste-based models (Becker 1971), the evaluator instead has a preference for hiring members of the dominant group; say, men. Also, an evaluator's self-image bias (Siniscalchi and Veronesi 2020) or type-based mentoring (Athey et al. 2000) can perpetuate gender imbalance. I draw on experimental evidence that discrimination widens labour market differences between women and men in male occupations (Riach and Rich 2006), and that women can suffer from discrimination based on their physical appearance (Alaref et al. 2020).

Blind auditions are studied by Taylor and Yildirim (2011), focusing on the effort and selection effects when the evaluator observes a signal of performance quality. Their model can explain the association of blind auditions with an increased probability of hiring females through a form of statistical discrimination, as a blind audition forces the evaluator to ignore the applicant's ability. Similar to Taylor and Yildirim (2011), I study the conditions under which a blind audition provides better effort incentives. However, I allow for taste-based discrimination of the evaluator so that a blind audition forces him to ignore the applicant's ability and gender. In my model, females and males are equally productive for the same level of ability. This assumption stresses that prejudices against female musicians (Seltzer 1989), social attitudes (Allmendinger and Hackman 1995) and self-identity (Starr 1974) are key in explaining the findings of Goldin and Rouse (2000).

When the evaluator in Taylor and Yildirim (2011) can commit to an acceptance threshold prior to the audition and the observed quality signal is verifiable, he is forced to reject performances that he knows to be of high quality with positive probability to provide effort incentives. Such a trade-off at the high end of the quality spectrum does not arise in my informed audition; rather, applicants with low ability may be screened as they anticipate a lower probability of being hired. Moreover, in Taylor and Yildirim's (2011) blind audition, the evaluator uses a uniform acceptance threshold. My blind audition, in contrast, allows for signalling concerns: a uniform hiring probability only arises when applicants pool on high effort.

In Taylor and Yildirim (2011), if the applicant pool is of mainly high ability, the evaluator prefers a blind audition as assessing performance quality is less important than providing effort incentives; if the applicant pool is of predominantly low ability, the evaluator prefers an informed audition as selecting high-quality performances is crucial. Taste-based discrimination, in contrast, allows for richer predictions: if there is little bias and the applicant pool is highly able, my blind audition attracts low-ability applicants rather than providing targeted effort incentives. For a high bias, the evaluator prefers a blind audition irrespective of the applicant pool's ability composition. 
In Taylor and Yildirim (2011), if the signal of performance quality is precise, the evaluator prefers a blind audition as the incremental information from observing ability is low; if imprecise, he prefers an informed audition as observing ability has a large incremental informational value. My model, in contrast, makes more nuanced predictions about the effect of performance uncertainty: if there is little bias, informed auditions are preferred irrespective of the degree of performance uncertainty. If the bias is high and performance uncertainty is above a threshold, the ability composition of the applicant pool determines the evaluator's preferences. For a very low prior about ability, it is paramount to include ability in the hiring policy. While blind auditions provide better effort incentives for the highly able, these types are infrequent. For a sufficiently high prior, high effort incentives for the highly able are paramount, making blind auditions preferable.

The remainder of this paper is structured as follows. Section 2 sets out preliminaries common to both auditions. In Sects. 3 and 4, I solve for equilibrium in the informed and blind audition. Section 5 details my main results on the evaluator's and applicant's audition preferences. I introduce asymmetric uncertainty in Sect. 6. I compare blind auditions to quotas and subsidies in Sect. 7. I briefly highlight the agency cost in the two audition forms in Sect. 8. I discuss the use of gender-blind CVs in Sect. 9 and conclude with avenues for further research in Sect. 10.

\section{Preliminaries}

In this section, I set out the timing, preferences of players, assumptions and solution concepts.

\subsection{Timing}

Two risk neutral parties, an applicant (she) and an evaluator (he), play a three-stage game.

In the first stage, the evaluator commits to a blind $(B)$ or an informed $(I)$ audition given an exogenously determined wage. If the audition is informed, the evaluator learns the applicant's type $\theta:=(\eta, g)$, where $\eta \in\left\{\eta_{L}, \eta_{H}\right\}$ is ability ${ }^{10}$ and $g \in\{m, f\}:=\{0,1\}$ is gender. If the audition is blind, the evaluator does not learn the applicant's type. He only knows the type distribution: the applicant is female or male with equal probability and the applicant is of high ability with $\operatorname{Pr}\left(\eta_{H}\right):=p \in(0,1)$. It is common knowledge that ability and gender are independent.

\footnotetext{
10 Ability may equate to an artist's creativity (Towse 2006). See also Duff's (1767) classic work on original genius: a highly able applicant may have the right combination of imagination, judgment and taste to (i) prepare an original performance for the audition, and (ii) reduce the investment needed to attain a given level of mastery.
} 
In the second stage, the applicant moves, knowing her type and whether it is a blind or informed audition. She chooses how much costly effort ${ }^{11}$ to invest in preparing a performance, where effort $e \in\left\{e_{L}, e_{H}\right\}$ can be low or high and effort costs are $c(e)$. There is an outside option for the applicant that yields a zero payoff. In the third stage, the applicant delivers her performance. It can turn out to be of low or high quality; that is, $q \in\left\{q_{L}, q_{H}\right\}$.

The evaluator makes the hiring decision based on type $\theta$ (i.e. ability and gender) and performance quality $q$ if the audition is informed, and based on performance quality $q$ alone if the audition is blind. ${ }^{12}$ In either audition form, the evaluator has a random outside option $\bar{U}$, which he can revert to instead of hiring the applicant. I describe the evaluator's outside option and the determination of performance quality in more detail in Sect. 2.3.

\subsection{Preferences of players}

The evaluator is assumed to be biased against female applicants. This is represented in form of a bias parameter $\beta \in\left[0, q_{L}+\eta_{L}\right]$. The level of bias $\beta$ is common knowledge in either audition form. I formalise the evaluator's preferences with a gross utility function consisting of two parts:

$$
V(q, \eta, g)=f(q, \eta)-\beta g=q+\eta-\beta g .
$$

The first part $f(q, \eta)=q+\eta$ is a production function. ${ }^{13}$ The evaluator, therefore, prefers to hire an applicant who is of high ability and delivers a high-quality performance in stage 3. In particular, given the applicant's ability $\eta$, which the evaluator may learn in stage 1 , and her performance quality $q$, always observed in stage 3 , the evaluator earns revenue $f(q, \eta)$ by hiring the applicant. The assumption that performance quality and ability jointly determine revenue may be justified if $f(q, \eta)$ is regarded more broadly as an applicant's marketable talent, consisting of an endogenous component $q$ and an exogenous component $\eta .^{14}$ The inclusion of ability allows

\footnotetext{
${ }^{11}$ In the performing arts, an applicant's effort includes the time spent studying the set audition repertoire to determine which excerpt is appropriate, the time spent rehearsing the selected excerpt, etc. Without an effort choice, the game would reduce to a decision problem of the evaluator, forbidding the study of incentive effects in light of bias.

${ }^{12}$ An alternative interpretation of the game involves two evaluators: the senior management with a zero bias chooses the audition form in stage 1; the evaluator with a possibly nonzero bias chooses whom to hire in stage 3 . The senior management may have learned the bias only after assigning the evaluator to the task.

${ }^{13}$ Under a multiplicative form of the production function, $f(q, \eta)=q \eta$, most of the results remain qualitatively unchanged. If the applicant's ability did not enter the production function directly, there would not be a motive to signal high ability in the blind audition, providing targeted effort incentives at high biases in Section 4. Under $f(q)=q$, the evaluator would, however, not be indifferent between audition forms: for a moderate bias, he would prefer a blind audition for targeted effort incentives; for biases above a certain threshold, he would not hold an audition at all. The proofs are available on request.

${ }^{14}$ See Tsay and Banaji (2011) for the two sources of talent and how they are perceived by expert decision-makers: "naturals" are characterised by early evidence of high innate ability; "strivers" by high motivation and perseverance. Their substitutability is in line with Galenson's $(2006,2009)$ finding that there are two equally successful types of artists: experimental artists improve their work by trial and error; conceptual artists work with deductive certainty.
} 
for revenue-generating reputation effects from hiring highly able star soloists ${ }^{15}$ that have been shown to attract fans (Hart 1973, p. 390) and additional single-ticket buyers (Kamakura and Schimmel 2013). Furthermore, the functional form of $f(q, \eta)$ implies that males and females are perfect substitutes in production: gender does not enter. The second part $\beta g$ captures the evaluator's bias against female applicants. ${ }^{16}$

The evaluator faces four types of applicants in this game, $\Theta=\left\{\left(\eta_{L}, m\right)\right.$, $\left.\left(\eta_{H}, m\right),\left(\eta_{L}, f\right),\left(\eta_{H}, f\right)\right\}$. The applicant, whether of low or high ability, female or male, wants to be hired to receive a wage $w_{\theta}$ net of effort costs. In particular, by choosing $e \in\left\{e_{L}, e_{H}\right\}$ she maximises her expected utility $U$, taking into account how her effort choice influences the probability of being hired via its effect on performance quality:

$$
U(e, \eta, g)=\operatorname{Pr}(\text { hired } \mid \cdot) w_{\theta}-\frac{e^{2}}{2 \eta} .
$$

In an informed audition, the hiring probability depends on performance quality, gender and ability; that is, $\operatorname{Pr}($ hired $\mid q, \eta, g$ ). In a blind audition, in contrast, the hiring probability never directly depends on gender or ability; that is, $\operatorname{Pr}($ hired $\mid q)$. The applicant's effort costs are given by $c(e)=\frac{e^{2}}{2 \eta}$. Thus, ability determines the marginal cost of exerting high rather than low effort, with high ability corresponding to lower marginal costs. The applicant receives a zero payoff if she is not hired and her outside option gives zero utility.

\subsection{Assumptions and solution concept}

I assume that the evaluator's revenue from a high level of ability and performance quality is twice as large as from a low level, and that ability and performance quality are equally valuable to the evaluator.

Assumption $1 \eta_{L}=e_{L}=q_{L}=1$ and $\eta_{H}=e_{H}=q_{H}=2$.

Given that the bias is bounded such that a maximally biased evaluator's gross utility from hiring a low-ability female with a low-quality performance is zero, I can normalise the parameter levels in Assumption 1 without loss of generality: my model would deliver identical results if $\eta_{L}=e_{L}=q_{L}=x$ and $\eta_{H}=e_{H}=q_{H}=2 x$, where $x>0$. Assumption 1 keeps my model tractable but rules out general conclusions on the effect of blind auditions: my model provides insights when the

\footnotetext{
15 See also the economics literature on the phenomenon of superstars (Adler 1985; Rosen 1981).

16 This form of the utility function is inspired by (Becker 1971, chap. 3, p. 39): an employer has a taste parameter $d$ ("coefficient of discrimination") so that the wage of a member of the minority group $N$ is effectively $w_{N}+d$.
} 
relationship between ability, effort and performance quality is balanced from the evaluator's perspective. ${ }^{17}$

I assume that the evaluator always fills the position by either hiring the applicant at a wage $w_{\theta}$ or a uniformly distributed outside option at a wage $w_{\bar{U}}$. An unfilled orchestra position during the playing season, for example, would be prohibitively costly. As concert schedules are planned far in advance, ticket sales tend to start months before the performances and orchestral parts need to be acquired and allocated prior to rehearsals (Towse 2010, chap. 8), the evaluator is unlikely to leave such a position unfilled.

\section{Assumption $2 \bar{U} \sim \mathcal{U}[2-\beta, 4]$.}

The value of $\bar{U}$ is unknown to the evaluator when making the hiring decision. The bounds on the outside option in Assumption 2 may be justified if $\bar{U}$ is thought of as the possibility to engage a substitute from an agency. This substitute generates gross utility of at least $2-\beta$ if she is of type $\theta=\left(\eta_{L}, f\right)$ and provides a low performance quality. The substitute generates at most 4 if he is of type $\theta=\left(\eta_{H}, m\right)$ and provides a high performance quality. Because the evaluator cannot contract upon the substitute's type and performance quality with the agency, $\bar{U}$ is essentially a gamble that may turn out to be better or worse than the applicant considered in stage 3 of the game. Given this interpretation, a greater bias against female applicants naturally reduces the minimum value of the outside option. In fact, the outside option may turn out to be of no value to a maximally biased evaluator. Continuity is assumed for tractability; however, it implies a discrepancy between the number of types of the outside option and the applicant in the model.

I assume that the evaluator pays wage $w$ whether he hires an applicant of type $\theta$ or the outside option, and that the wage received by the applicant and the outside option is exogenously determined by the outside option's expected value $\mathbb{E}[\bar{U}]$.

Assumption $3 w:=w_{\theta}=w_{\bar{U}}$ for all $\theta \in \Theta$ and $w=\mathbb{E}[\bar{U}]$.

Assumption 3 is in line with orchestras' practice to specify a base pay according to which positions are remunerated, standardising wages across audition forms

\footnotetext{
17 A more general framework where high talent $\left(\eta_{H}\right.$ and $\left.q_{H}\right)$ can be more or less than twice as valuable allows for qualitatively different equilibria: a low value coupled with a high bias, for example, will discourage all females from participating in an informed audition while attracting all males with no incentive to exert high effort given their possibility to identify themselves as male. A blind audition in this setting will not provide targeted effort incentives either but may at least achieve gender balance in the applicant pool that participates in the audition. A more general framework where a given level of ability and performance quality need not be equally valuable eliminates the symmetry $\operatorname{Pr}\left(h \mid q_{L}, \eta_{H}, \cdot\right)=\operatorname{Pr}\left(h \mid q_{H}, \eta_{L}, \cdot\right)$ in an informed audition: when performance quality becomes slightly more valuable, low-ability males are attracted at even lower biases but the highly able exert high effort at greater biases. In this setting, the evaluator's bias must be more severe before a blind outperforms an informed audition, and at extreme biases the blind audition may increase the applicant pool that participates rather than reducing it to the highly able.
} 
for applicants and the outside option. ${ }^{18}$ Furthermore, fixing the wage at the expected value of the outside option captures that trade unions tend to be integrated in the setting of the base pay to performers (Towse 2010): the base pay reflects the market value of the outside option ex-ante and is the evaluator's maximum willingness-topay when negotiating with unions. Given Assumption 3, I can abstract from wages in the evaluator's utility function (1). Wage costs are sunk and do not affect his hiring decision in stage 3. Later, I will refer to the evaluator's utility net of wage costs as $\Pi$.

In the benchmark model, I focus on the interaction of the strength of the evaluator's bias and the information structure of the audition.

Assumption $4 \operatorname{Pr}\left(q_{i} \mid e_{i}\right)=1$ for $i \in\{L, H\}$.

Assumption 4 abstracts from any moral hazard considerations: effort maps oneto-one into performance quality, so can be perfectly inferred by the evaluator. In Section 6, I relax this assumption and allow for moral hazard by considering a setting where low effort can result in low or high performance quality. Given Assumption 4, an informed audition is a game of complete information, and the solution concept is backward induction. A blind audition is a game of incomplete information, and the solution concept is perfect Bayesian equilibrium, refined by the D1-Criterion when necessary.

\section{Informed audition}

If the evaluator has committed to an informed audition, stage 2 and 3 are a game of complete information with four proper subgames, one for each applicant type. I, therefore, solve the game by first considering the evaluator's hiring decision in stage 3. Using this decision, I then determine the applicant's optimal effort choice in stage 2 .

\subsection{Hiring decision of evaluator}

The evaluator compares the utility from hiring the applicant to the value from hiring the outside option. Therefore, he hires the applicant in stage 3 with probability

$$
\begin{aligned}
\operatorname{Pr}(\text { hired } \mid q, \eta, g):=\operatorname{Pr}(\bar{U} \leq V(q, \eta, g)) & =\frac{V(q, \eta, g)-(2-\beta)}{4-(2-\beta)}, \\
& =\frac{q+\eta+\beta(1-g)-2}{2+\beta} .
\end{aligned}
$$

\footnotetext{
18 In the UK, for example, employment agreements are negotiated by the Musicians' Union (n.d.) and applicable to members employed with major orchestras. The assumption also eliminates the screening aspect that wage setting would otherwise have in stage 1 . In particular, endogenising wages would make a blind audition preferable even for an unbiased evaluator due to significant wage savings. Furthermore, the evaluator would then be best off setting $w=0$, always hiring the outside option because $\bar{U}$ does not respond to incentives in this model.
} 
Intuitively, the evaluator considers how likely it is that the substitute from an agency will deliver a gross utility less than $V(q, \eta, g)$ from hiring the applicant and makes this probability his hiring rule.

Given Assumption 4 and the hiring rule (3), there are eight possible hiring probabilities in an informed audition:

$$
\begin{array}{ll}
\operatorname{Pr}\left(h \mid q_{L}, \eta_{L}, f\right)=0, & \operatorname{Pr}\left(h \mid q_{L}, \eta_{L}, m\right)=\frac{\beta}{2+\beta}, \\
\operatorname{Pr}\left(h \mid q_{H}, \eta_{L}, f\right)=\operatorname{Pr}\left(h \mid q_{L}, \eta_{H}, f\right)=\frac{1}{2+\beta}, & \operatorname{Pr}\left(h \mid q_{H}, \eta_{L}, m\right)=\operatorname{Pr}\left(h \mid q_{L}, \eta_{H}, m\right)=\frac{1+\beta}{2+\beta}, \\
\operatorname{Pr}\left(h \mid q_{H}, \eta_{H}, f\right)=\frac{2}{2+\beta}, & \operatorname{Pr}\left(h \mid q_{H}, \eta_{H}, m\right)=1 .
\end{array}
$$

Importantly, the evaluator never hires a low-ability-low-effort female in an informed audition: by reverting to the outside option, he can never do worse but may be lucky to engage a substitute of higher ability, higher effort or different gender. On the other hand, the evaluator always hires a high-ability-high-effort male: by reverting to the outside option, the evaluator cannot do any better. The remaining hiring probabilities depend on the strength of the evaluator's bias. Intuitively, for females, the hiring probabilities are decreasing in $\beta$. For males, those are increasing in $\beta$.

\subsection{Effort decision of applicant}

Given the hiring probabilities, the applicant chooses effort to maximise her expected utility (2). To determine her optimal effort response as a function of the bias, I compare the participation and incentive constraint for each applicant type.

Lemma 1 The effort responses of the four applicant types partition the evaluator's bias $\beta \in[0,2]$ into three regions: (i) For a low bias, $\beta \in \beta_{I}^{L}:=\left[0, \frac{5-\sqrt{17}}{2}\right)$, only high-ability applicants participate and exert high effort. ${ }^{19}$ (ii) For a moderate bias, $\beta \in \beta_{I}^{M}:=\left[\frac{5-\sqrt{17}}{2}, \frac{6}{5}\right]$, low-ability males also participate and exert low effort. (iii) For a high bias, $\beta \in \beta_{I}^{H}:=\left(\frac{6}{5}, 2\right]$, all applicants except low-ability females participate and exert low effort.

Proof Detailed proofs of all results are in Appendix A.

The partition of the evaluator's bias into three regions is illustrated in Fig. 1. The low and moderate bias cover roughly 21.9 and 38.1 percent of the parameter space, respectively. The high bias is the largest interval, covering 40 percent.

$\overline{19}$ Note that $(5-\sqrt{17}) / 2 \approx 0.44$. 


\subsection{Expected utility of evaluator}

The evaluator's prior is that the applicant is equally likely to be a female or male when committing to the audition form. Furthermore, he knows that the applicant is of high ability with probability $p \in(0,1)$, and that ability is independent of gender. Hence, all four proper subgames are reached with nonzero probability and are, thus, relevant when deriving the evaluator's expected net utility for different values of $\beta$.

\section{Proposition 1}

(i) Suppose $\beta \in \beta_{I}^{L}$ where $\beta_{I}^{L}$ is defined as in Lemma 1(i). Then,

$\mathbb{E}\left[\Pi_{I} \mid \beta \in \beta_{I}^{L}\right]:=\mathbb{E}\left[V \mid \beta \in \beta_{I}^{L}\right]-w=\frac{p}{2}\left[\frac{2}{2+\beta}\left(1-\frac{\beta}{2}\right)+\left(1+\frac{\beta}{2}\right)\right]>0$.

(ii) Suppose $\beta \in \beta_{I}^{M}$ where $\beta_{I}^{M}$ is defined as in Lemma 1(ii). Then,

$\mathbb{E}\left[\Pi_{I} \mid \beta \in \beta_{I}^{M}\right]:=\mathbb{E}\left[V \mid \beta \in \beta_{I}^{M}\right]-w$,

$$
=\frac{1-p}{2}\left[\frac{\beta}{2+\beta}\left(\frac{\beta}{2}-1\right)\right]+\frac{p}{2}\left[\frac{2}{2+\beta}\left(1-\frac{\beta}{2}\right)+\left(1+\frac{\beta}{2}\right)\right] \gtrless 0 .
$$

(iii) Suppose $\beta \in \beta_{I}^{H}$ where $\beta_{I}^{H}$ is defined as in Lemma 1(iii). Then,

$$
\begin{aligned}
\mathbb{E}\left[\Pi_{I} \mid \beta \in \beta_{I}^{H}\right] & :=\mathbb{E}\left[V \mid \beta \in \beta_{I}^{H}\right]-w, \\
& =\frac{1-p}{2}\left[\frac{\beta}{2+\beta}\left(\frac{\beta}{2}-1\right)\right]+\frac{p}{2}\left[\frac{1}{2+\beta}\left(-\frac{\beta}{2}\right)+\frac{1+\beta}{2+\beta}\left(\frac{\beta}{2}\right)\right] \gtrless 0 .
\end{aligned}
$$

If the evaluator's bias is low, he breaks even in subgame $\left(\eta_{L}, f\right)$ and $\left(\eta_{L}, m\right)$ and expects positive net utility in subgame $\left(\eta_{H}, f\right)$ and $\left(\eta_{H}, m\right)$. Intuitively, when the evaluator is almost impartial, requiring a $\mathrm{CV}$ acts as an effective means to screen applicants by ability and to provide targeted effort incentives: high effort incentives exclusively for high-ability applicants while low-ability applicants do not participate. If the bias is moderate, the evaluator instead expects negative net utility in subgame $\left(\eta_{L}, m\right)$ as low-ability males exert low effort rather than dropping out. Low-ability males essentially exploit the evaluator's bias: when they know the bias to be moderate, the probability of being hired conditional on exerting low effort and identifying themselves as male is sufficiently high to make the cost of low effort worthwhile. If the evaluator is highly biased, he also expects negative net utility in subgame $\left(\eta_{H}, f\right)$. Intuitively, when high-ability females know the evaluator's bias to be substantial, the marginal cost from putting in high rather than low effort outweighs the marginal benefit from being hired more often. They are deterred from exerting high effort at such a high bias. ${ }^{20}$ Moreover, high-ability males rest on their laurels and have little incentive to exert high effort. Their benefit from exploiting the bias and being able

${ }^{20}$ The mechanism is similar to stereotype threats (Günther et al. 2010). 


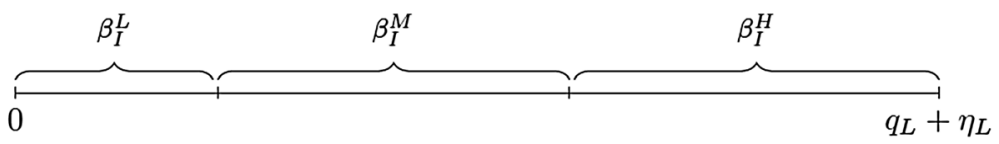

Fig. 1 Partition of the evaluator's bias in an informed audition

to identify themselves as male makes the increase in cost from exerting high rather than low effort not worthwhile.

Proposition 1 highlights the role of ability. For a low bias, the evaluator's expected net utility (4) is increasing in the prior that the applicant is of high ability. An increasingly able applicant pool makes it more likely that the evaluator faces the profitable subgame $\left(\eta_{H}, f\right)$ or $\left(\eta_{H}, m\right)$ relative to the subgames in which he breaks even with the outside option. For a moderate bias, the increase in the evaluator's expected net utility (5) is more pronounced: as subgame $\left(\eta_{L}, m\right)$ becomes less likely, the evaluator is able to avoid the losses from potentially hiring low-ability males who participate in the audition. For a high bias, the increase in the evaluator's expected net utility (6) is more attenuated: as $p$ increases, the evaluator faces both the unprofitable subgame $\left(\eta_{H}, f\right)$ and the profitable subgame $\left(\eta_{H}, m\right)$ more often.

\section{Blind audition}

In a blind audition, the evaluator does not learn the applicant's type $\theta$ in stage 1 . He only observes her performance quality $q$ in stage 3 . Thus, there are no proper subgames but two information sets: $q_{L}$ and $q_{H}$. Each information set contains four nodes when the evaluator has to make the hiring decision in stage 3 . Because these information sets are non-singletons, stage 2 and 3 in a blind audition are a game of incomplete information. Therefore, I specify beliefs for the evaluator: a probability distribution over the nodes in both $q_{L}$ and $q_{H}$. Intuitively, this probability distribution constitutes the evaluator's revised beliefs how likely it is, upon hearing a low- or high-quality performance, that he is facing a particular applicant type behind the curtain. In what follows, I focus on the case when the bias is either sufficiently low to induce all applicants to exert high effort or sufficiently high to induce only the highly able to exert high effort. ${ }^{21}$ I refer to the former case as pooling and the latter case as separating.

\footnotetext{
${ }^{21}$ I do not consider applicants pooling on low effort as my focus is on whether, and under which conditions, blind auditions can be superior. To see why this can never obtain in a low-effort pooling equilibrium, compare it to the worst-case scenario in an informed audition; that is, for $\beta \in \beta_{I}^{H}$, all applicants except low-ability females exert low effort. This scenario gives the evaluator still a higher payoff because attracting low-ability-low-effort females is never profitable. The evaluator could have broken even with the outside option and, therefore, is worse off.
} 


\subsection{Pooling equilibrium}

Suppose the evaluator's bias is sufficiently low to induce all applicants to exert high effort. However, when observing a low performance quality off the equilibrium path, the evaluator believes the applicant to be of low ability. Upon observing a low-quality performance, the evaluator can, therefore, infer the applicant's ability from her action and expects gross utility

$$
\mathbb{E}\left[V \mid q_{L}\right]=q_{L}+1-\frac{\beta}{2}=2-\frac{\beta}{2}
$$

from hiring the applicant. ${ }^{22}$ Upon observing a high-quality performance, the evaluator cannot infer the applicant's ability and holds a belief that is equal to his prior. He expects gross utility

$$
\mathbb{E}\left[V \mid q_{H}\right]=q_{H}+\mathbb{E}\left[\eta \mid q_{H}\right]-\frac{\beta}{2}=2+[(1-p)+2 p]-\frac{\beta}{2}=3+p-\frac{\beta}{2}
$$

from hiring the applicant. The evaluator compares the expected utility from hiring the applicant to the value from hiring the outside option. Therefore, he hires the applicant at each information set with probability

$$
\begin{aligned}
\operatorname{Pr}(\text { hired } \mid q):=\operatorname{Pr}(\bar{U} \leq \mathbb{E}[V \mid q]) & =\frac{\mathbb{E}[V \mid q]-(2-\beta)}{4-(2-\beta)}, \\
& =\frac{q+\mathbb{E}[\eta \mid q]-\frac{\beta}{2}-(2-\beta)}{2+\beta} .
\end{aligned}
$$

Given Assumption 4 and the hiring rule (7), there are two possible hiring probabilities for both female and male applicants:

$$
\begin{aligned}
& \operatorname{Pr}\left(h \mid q_{L}\right)=\operatorname{Pr}\left(\bar{U} \leq 2-\frac{\beta}{2}\right)=\frac{\beta}{4+2 \beta}, \\
& \operatorname{Pr}\left(h \mid q_{H}\right)=\operatorname{Pr}\left(\bar{U} \leq 3+p-\frac{\beta}{2}\right)=\frac{2(1+p)+\beta}{4+2 \beta} .
\end{aligned}
$$

Compared to an informed audition, female and male applicants now face the same hiring probabilities as the evaluator cannot bias gender. Similarly, high- and lowability applicants face the same hiring probabilities as they cannot identify themselves in a pooling blind audition. Furthermore, an increasingly skilled applicant pool raises the evaluator's expected revenue from hiring at $q_{H}$. Hence, he finds it optimal to hire more often at this information set.

\footnotetext{
22 The evaluator cannot infer gender in a pooling or separating blind audition because, with $\eta$ fixed, females and males have the same payoff structure. In effect, the evaluator now faces only two applicant types, $\eta_{L}$ and $\eta_{H}$.
} 


\subsubsection{Effort decision of applicant}

Given the two hiring probabilities, the applicant chooses effort to maximise her expected utility (2). I now show that the prior determines whether a high-effort pooling equilibrium can be supported, and that $p$ places an upper bound on the evaluator's bias in any such pooling equilibrium. I define $\beta(p):=\left\{\beta: U\left(e_{H}, \eta_{L}\right)=0\right\}$.

Lemma 2 (i) For $p<\frac{1}{3}$, no high-effort pooling equilibrium exists. (ii) For $p=\frac{1}{3}$, a high-effort pooling equilibrium exists if the evaluator is unbiased. (iii) For $\frac{1}{3}<p<1$, a high-effort pooling equilibrium exists if $\beta \in \beta_{B}^{L}:=[0, \beta(p)]$, where $\beta^{\prime}(p)>0$. As $p \uparrow 1$, the upper bound on the pooling equilibrium $\beta(p)$ approaches the infimum beyond which a separating equilibrium exists (Lemma 3 ).

With the observation that it is always optimal for high-ability applicants to exert high effort if it is optimal for low-ability applicants to exert high effort, pooling on high effort is possible if the prior that the applicant is of high ability is sufficiently large and the evaluator's bias is not too high. Furthermore, an increasingly able applicant pool makes it easier for the fewer low-ability to hide behind the more-andmore high-ability applicants.

\subsubsection{Expected utility of evaluator}

While the evaluator does not learn the applicant's type, the applicant's payoff structure is common knowledge. In particular, for the evaluator's $q_{H}$-belief that all applicants exert high effort to be consistent with the applicants' effort decision, he needs to have a sufficiently low bias.

Proposition 2 Suppose $\beta \in \beta_{B}^{L}$ with $\frac{1}{3} \leq p<1$ where $\beta_{B}^{L}$ is defined as in Lemma 2. Then,

$$
\mathbb{E}\left[\Pi_{B} \mid \beta \in \beta_{B}^{L}\right]:=\mathbb{E}\left[V \mid \beta \in \beta_{B}^{L}\right]-w=p \frac{2(1+p)+\beta}{4+2 \beta}>0 .
$$

The evaluator's expected net utility (8) is increasing in the prior that the applicant is of high ability because, ceteris paribus, an increasingly skilled applicant pool raises the evaluator's expected revenue from hiring in a pooling blind audition. Intuitively, the revised belief of the evaluator upon observing a high-quality performance takes into account that it is ex-ante more likely to face a high-ability female or a high-ability male behind the curtain.

\subsection{Separating equilibrium}

Suppose the evaluator's bias is sufficiently high that only high-ability applicants exert high effort. As before, the evaluator believes the applicant to be of low ability when observing a low performance quality. Therefore, the evaluator has degenerate 
posterior beliefs at both information sets. Upon observing a low-quality performance, he holds the belief that the applicant is of low ability with probability one, and male or female with equal probability. Upon observing a high-quality performance, he believes the applicant to be of high ability with probability one, and male or female with equal probability. At $q_{L}$, the evaluator's expected gross utility $\mathbb{E}\left[V \mid q_{L}\right]=2-\frac{\beta}{2}$ from hiring the applicant is unchanged. At $q_{H}$, the evaluator can now infer the applicant's ability from her action and expects gross utility

$$
\mathbb{E}\left[V \mid q_{H}\right]=q_{H}+2-\frac{\beta}{2}=4-\frac{\beta}{2}
$$

from hiring the applicant. As before, the evaluator compares the expected utility from hiring the applicant to the value from hiring the outside option. Given Assumption 4 and the hiring rule (7), there are two possible hiring probabilities for both female and male applicants:

$$
\begin{aligned}
& \operatorname{Pr}\left(h \mid q_{L}\right)=\operatorname{Pr}\left(\bar{U} \leq 2-\frac{\beta}{2}\right)=\frac{\beta}{4+2 \beta}, \\
& \operatorname{Pr}\left(h \mid q_{H}\right)=\operatorname{Pr}\left(\bar{U} \leq 4-\frac{\beta}{2}\right)=\frac{4+\beta}{4+2 \beta} .
\end{aligned}
$$

\subsubsection{Effort decision of applicant}

Given the two hiring probabilities, the applicant chooses effort to maximise her expected utility (2).

Lemma 3 For $\beta \in \beta_{B}^{H}:=(\sqrt{17}-3,2)$, a separating equilibrium exists in which only high-ability applicants exert high effort and low-ability applicants do not participate.

Separation is possible if the bias is sufficiently high so that it is too costly for lowability applicants to participate. Moreover, for $\beta<2$, the outside option dominates low effort for low-ability applicants. For $\beta \leq 2$, high effort dominates low effort for high-ability applicants.

\subsubsection{Expected utility of evaluator}

For the evaluator's $q_{H}$-belief that only high-ability applicants exert high effort to be consistent with the applicants' effort decision, he needs to have a sufficiently high bias. In this case, low-ability applicants do not participate and $q_{L}$ is not reached. Therefore, the evaluator's belief at this information set is not determined by the applicant's equilibrium play. I provide a robustness check in "Appendix" $\mathrm{C}$ of the working paper: two refinements based on either deviation payoffs or the 
D1-Criterion show that the evaluator's belief that the applicant is of low ability when observing a deviation to $q_{L}$ constitutes a reasonable restriction.

Proposition 3 Suppose $\beta \in \beta_{B}^{H}$ where $\beta_{B}^{H}$ is defined as in Lemma 3. Then,

$$
\mathbb{E}\left[\Pi_{B} \mid \beta \in \beta_{B}^{H}\right]:=\mathbb{E}\left[V \mid \beta \in \beta_{B}^{H}\right]-w=p \frac{4+\beta}{4+2 \beta}>0 .
$$

As before, the evaluator's expected net utility (9) is increasing in the prior that the applicant is of high ability. However, the channel through which an increase in the prior leads to an increase in the evaluator's profit is less pronounced. This is because, in a pooling blind audition, an increase in the prior also implied a reduction in the probability that, upon observing a high-quality performance, the evaluator faced a low-ability female or low-ability male behind the curtain.

\section{Comparison of auditions}

Having discussed the evaluator's net utility in both audition forms, I can conclude under which conditions on the bias and the prior the evaluator prefers a blind or informed audition to maximise his expected net utility.

Proposition 4 (i) For $\frac{1}{3} \leq p<1$, if the evaluator's bias against female applicants is low, $\beta \in \beta_{B}^{L}$, he prefers an informed audition over a pooling blind audition. (ii) For $0<p<1$, if the evaluator's bias against female applicants is high, $\beta \in \beta_{I}^{H} \cap \beta_{B}^{H}$, he prefers a separating blind audition. (iii) For $0<p<\frac{2-\beta}{2}$, if the evaluator's bias against female applicants is moderate, $\beta \in \beta_{I}^{M} \cap \beta_{B}^{H}$, he prefers a separating blind audition. (iv) For $\frac{2-\beta}{2}<p<1$, if the evaluator's bias against female applicants is moderate, $\beta \in \beta_{I}^{M} \cap \beta_{B}^{H}$, he prefers an informed audition.

Proposition 4 details my main result on the evaluator's audition preferences: there exists a threshold bias above which the evaluator is better off having no information about the applicant's type. In this case, a blind audition provides targeted effort incentives. In an informed audition, in contrast, the evaluator's bias would distort effort incentives: all applicants except low-ability females would exert low effort. Consequently, committing to no information can be beneficial for the evaluator. This prediction of my model echoes the insight of Gladwell (2005) regarding first impression biases: "by fixing the first impression at the heart of the audition - by judging purely on the basis of ability - orchestras now hire better musicians, and better musicians mean better music" (p. 253).

Conversely, the evaluator is better off having more information if his bias against female applicants is low. An informed audition allows him to attract a pool of exclusively high-ability applicants. Moving to a blind audition would also induce lowability applicants to participate and exert high effort if the evaluator's prior is sufficiently high (Fig. 2a, b). Moreover, a blind audition would prevent the evaluator from discriminating between applicants of different characteristics: when all exert 
high effort, the evaluator has no means of distinguishing them behind the curtain. Specifically, he can no longer hire a high-ability-high-effort male with probability one. However, reverting to the outside option with positive probability when highability males exert high effort can only make the evaluator worse off due to the upper bound on $\bar{U}$. This prediction of my model is in line with Holland (1981), observing that "equal opportunity has unloosed such an avalanche of auditionees that standards of selection and fairness are sometimes actually lowered" and that "[a]s a result, top talent is sometimes lost in the shuffle".

In Taylor and Yildirim's (2011) statistical discrimination model, an unbiased evaluator can prefer a blind audition as it provides better effort incentives than an informed audition. In my benchmark without taste-based discrimination $(\beta=0)$, in contrast, the evaluator prefers an informed audition: if at least one in three applicants is expected to be of high ability, a blind audition would lead to an avalanche of auditionees; a blind audition only provides better (i.e. targeted) effort incentives if there is at least some taste-based discrimination, and $\beta$ exceeds some threshold.

For a small range of moderate biases, $\beta \in \beta_{I}^{M} \cap \beta_{B}^{H}$, both a blind and informed audition provide high effort incentives for high-ability applicants. However, the evaluator faces the distortion that an informed audition also attracts low-ability males, who exert only low effort. The prior determines the size of the loss from potentially hiring those types and, thus, whether the evaluator may be better off in a separating blind audition. First, for a range of priors from $\frac{2}{5}$ to $\frac{5-\sqrt{17}}{2} \approx 0.44$, the evaluator's preferences over auditions are non-monotonic in his bias (Fig. 3). Intuitively, this is because equation (5) is upward-sloping, whereas equation (9) is downward-sloping on the interval $\beta_{I}^{M} \cap \beta_{B}^{H}$. However, if the applicant pool is of predominantly low ability, the evaluator always prefers a blind audition for this range of moderate biases: it is an effective means to provide targeted incentives while reaping the benefits from breaking even with the outside option (Fig. 2c). The evaluator avoids substantial losses which he would have incurred in an informed audition from hiring low-ability males relatively frequently. As the applicant pool becomes increasingly able, however, this concern becomes less important. In particular, for a sufficiently high prior, the benefit from being able to hire high-ability females and high-ability males with differing probabilities outweighs the loss from potentially hiring a low-ability-loweffort male in an informed audition.

To gain some intuition behind the evaluator's distribution of preferences, suppose that the bias and the prior on high ability are drawn uniformly from their respective supports. In other words, all points in Fig. 3 are equally likely before the three-stage game is played. Therefore, I can calculate the ex-ante percentage with which a blind audition (red area) is preferred relative to an informed audition (blue area). In so doing, I discount the white areas for which no comparison is possible. The evaluator prefers a blind audition approximately sixty-four percent and an informed audition only approximately thirty-six percent of the time. Therefore, a simple form of heterogeneity in the bias across evaluators and in the ability composition across applicant pools may rationalise the observed co-existence of blind and informed auditions in the economy. Furthermore, it may rationalise that the majority of US symphony orchestras use a blind audition as an outcome of optimisation (Goldin and Rouse 2000). 


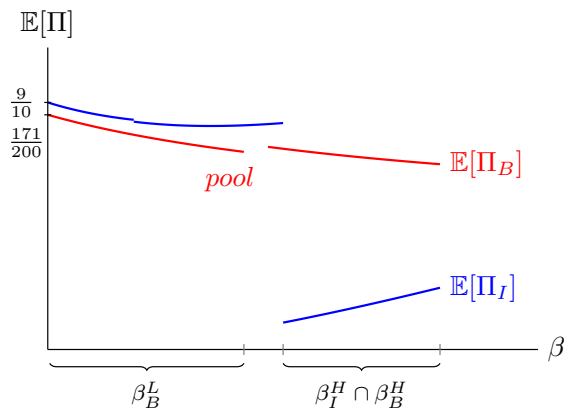

(a) $\operatorname{Pr}\left(\eta_{H}\right)=0.9$.



(b) $\operatorname{Pr}\left(\eta_{H}\right)=0.5$.

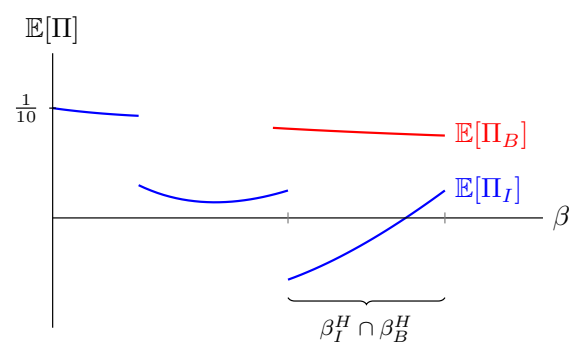

(c) $\operatorname{Pr}\left(\eta_{H}\right)=0.1$.

Fig. 2 Evaluator's expected net utility in a blind and informed audition

\subsection{Applicant preferences over auditions}

To complement the discussion of the evaluator's optimal audition form, I consider the applicant's audition preferences. In particular, having solved for optimal effort levels in both audition forms, I can conclude under which conditions on the bias and prior each type prefers a blind or an informed audition to maximise her expected utility.

Proposition 5 (i) A low-ability female prefers a blind audition if the evaluator's bias against female applicants is low; that is, $\beta \in \beta_{B}^{L}$. (ii) She is indifferent if the evaluator's bias against female applicants is high; that is, $\beta \in \beta_{B}^{H}$.

Intuitively, a low-ability female benefits from the move to a blind audition under the condition that the applicant pool is predominantly of high ability and the evaluator's bias is sufficiently low; for example, she benefits for biases weakly below $\beta(0.5) \approx 0.37$ when the prior is one-half (Fig. 4a). It allows her to pool with high-ability applicants, concealing her low ability and gender, and, thus, be hired with nonzero probability. In an informed audition, she would never participate because having to reveal both gender and ability would play out against her. When the evaluator's bias is instead high, she is indifferent since her best response is not to participate in either audition form. 




Fig. 3 Evaluator's preferences over auditions for different biases and priors

Proposition 6 (i) A high-ability female prefers an informed audition if the evaluator's bias against female applicants is low. (ii) She prefers a blind audition if the evaluator's bias against female applicants is high; that is, $\beta \in \beta_{B}^{H}$.

To gain some insight, fix a prior that is sufficiently high such that the range of biases for which a high-ability female prefers an informed audition is determined by the intersection of $U_{B}$ and $U_{I}$ (Fig. $4 \mathrm{~b}$ ). Then, as the prior that the applicant is of high ability approaches one, the range of biases for which a high-ability female prefers an informed audition is shrinking and approaches zero. Intuitively, for this applicant, it becomes relatively more important to conceal her gender as the evaluator already knows that she is likely to be of high ability. Submitting a CV prior to the audition is of little value to her.

Proposition 7 (i) A low-ability male prefers a blind audition if the evaluator's bias against female applicants is low. (ii) He prefers an informed audition if the evaluator's bias against female applicants is high; that is, $\beta \in \beta_{B}^{H}$.

For a very low bias, the intuition behind Proposition 7 is akin to that for lowability females. A low-ability male benefits from the move to a blind audition under the condition that the applicant pool is predominantly of high ability and the evaluator's bias is sufficiently low (Fig. 4c). For this applicant, it is attractive to conceal his low ability in a pooling blind audition. He is, in essence, benefiting from an informational externality because the applicant pool is increasingly able. However, beyond a critical value of the bias, he trades off this advantage and rather identifies himself as low-ability male to reap the benefits of the evaluator's bias against female applicants. 


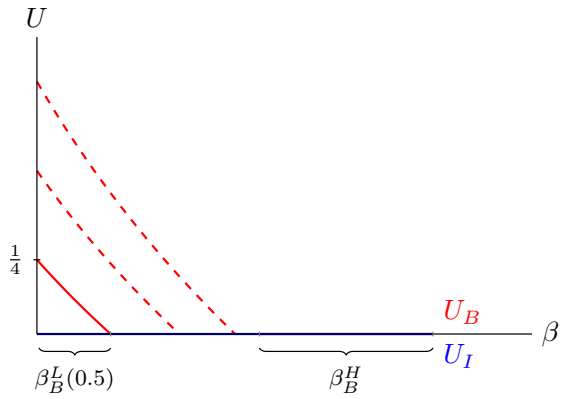

(a) Low-ability female.

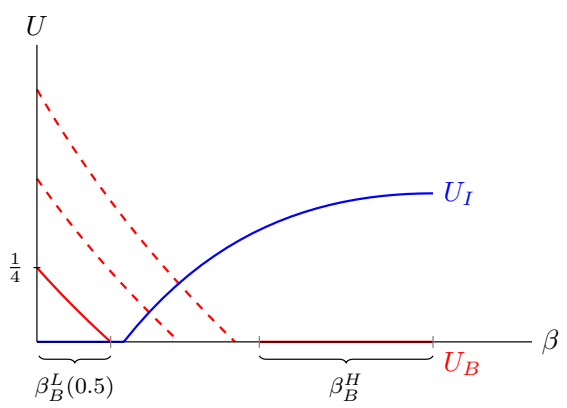

(c) Low-ability male.

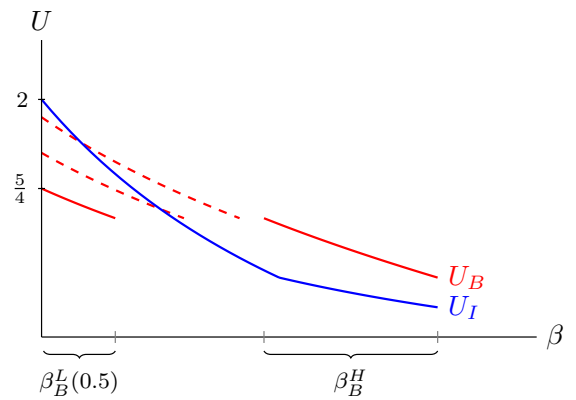

(b) High-ability female.

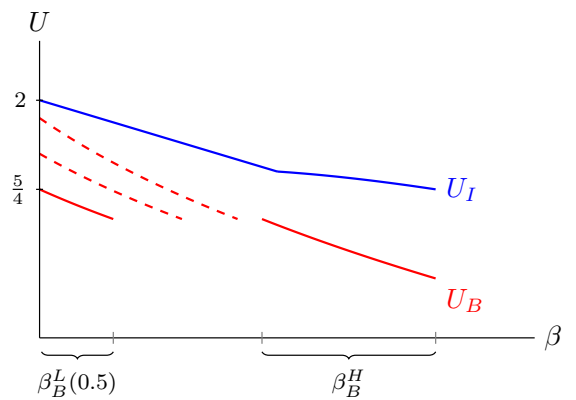

(d) High-ability male.

Fig. 4 Expected utilities in a blind and informed audition

Proposition 8 A high-ability male prefers an informed audition for all levels of bias.

Intuitively, a high-ability male never wants to conceal either his ability or gender, because his type always plays out in his favour. Under the condition that the evaluator's bias is strictly positive, even if the applicant pool was predominantly of high ability, he would benefit from submitting his CV to identify himself as a male. Graphically, this means that, for any strictly positive bias, $U_{B}$ will always be below $U_{I}$, even if the prior approaches one (Fig. 4d). This result contrasts with high-ability females whose preferences change to a blind audition as the applicant pool becomes increasingly skilled.

\subsection{Discussion of results}

Having discussed the preferences of the four applicant types, I conclude that, if the evaluator's bias is low, applicants' audition preferences differ along the ability dimension of their types. The highly able prefer to identify themselves as such in an informed audition, whereas the less able prefer to pool with them in a blind audition. In contrast, if the evaluator is highly biased, applicants' audition preferences differ 
along the gender dimension. Males prefer an informed audition as the bias plays out in their favour. High-ability females, on the other hand, prefer a blind audition: they rather trade off not being able to reveal their high ability for not having to reveal their gender.

Not surprisingly, the evaluator's preferences align with the preferences of highability applicants if his bias against females is low. The evaluator wishes to screen applicants by their ability. In this case, requiring a CV results in targeted effort incentives. High-ability applicants favour this policy as they want to distinguish themselves from low-ability applicants. More surprisingly, the evaluator's preferences align with the preferences of high-ability females if his bias is high. In this case, to provide targeted effort incentives, the evaluator does not require a $\mathrm{CV}$ and holds the audition behind a curtain. This deters low-ability applicants and, as a side effect, plays out in favour of high-ability females.

The predictions of my model are qualitatively in line with Goldin and Rouse's (2000) findings that "the switch to blind auditions can explain 30 percent of the increase in the proportion female among new hires and possibly 25 percent of the increase in the percentage female in the orchestras from 1970 to 1996" (p. 738). Yet, my model sheds light on the underlying forces. First, if there is at most a low bias against female applicants, such that audition preferences differ along the ability dimension, the authors' findings may be driven by the possibility of hiring lowability females in a blind audition. In fact, the nonzero probability of hiring lowability females outweighs the reduced probability of hiring high-ability females in a blind audition when the bias is low. To see this, note that the reduced probability is essentially the driver for why high-ability females prefer an informed audition, as their effort level remains unchanged. In other words, for the same effort cost they are less likely to be hired in a blind audition. Second, if the bias is high, such that audition preferences differ along the gender dimension, their findings may be driven by the increased probability of hiring high-ability females in a blind audition, with no change for their low-ability counterparts.

\section{Auditions under performance uncertainty}

Does a highly biased evaluator still prefer relying on a blindfolded performance if there is randomness in the environment? In the performing arts, such randomness is common; for example, due to varying temperature and humidity of the venue (Levinson 2017). Hence, it is important to understand whether the evaluator's audition preferences are affected by how strongly the applicant's performance quality correlates with her effort. I, thus, relax Assumption 4 in this section and provide an extension to asymmetric performance uncertainty.

Assumption $5 \operatorname{Pr}\left(q_{H} \mid e_{H}\right)=1$ and $\operatorname{Pr}\left(q_{L} \mid e_{L}\right)=1-\varepsilon$. 
Performance quality is stochastically determined by the applicant's effort and one additional uncertainty parameter $\varepsilon \in\left[0, \frac{1}{2}\right)$. As this parameter gets close to zero, the extended model approaches the benchmark model.

The asymmetry is motivated by the observation that high effort in the performing arts commonly takes the form of deliberate practice (Ericsson et al. 1993; Ericsson 2006), and learning about performance-controlling factors (McPherson and Schubert 2004). Performers often describe the process as one of overlearning and overpreparation (Hays and Brown 2006). Thus, deliberate practice removes the element of randomness in the mapping from high effort to high performance quality because it allows "the performance to become sufficiently part of oneself such that the response becomes automatic, regardless of what happens" (ibid., p. 99). Low effort, in contrast, does not have a deterministic outcome. In this case, "heat, light, noise, as well as any other conditions that might interfere with obtaining a fair assessment of an individual's performance" (Castiglione 1985, p. 34) can play a major role. Assumption 5 may also capture the inherent subjectivity in performance evaluation: the evaluator can identify who engaged in deliberate practice, but his standards are too lenient to always identify at the margin those applicants who did not. ${ }^{23}$

\subsection{Comparison of auditions under performance uncertainty}

I solve the model under performance uncertainty and discuss the effect on the evaluator's net utility in both audition forms in "Appendix" B of the working paper. In what follows, I summarise under which conditions on the bias, the prior and the degree of performance uncertainty my results on the evaluator's preferences continue to hold.

First, given performance uncertainty above a certain threshold, full separation in a blind audition is not possible. There is partial separation: highly able applicants exert high effort and the less able exert low effort. Therefore, this audition form does not have the same fully fledged effect as under certainty; that is, a blind audition cannot provide targeted effort incentives when the evaluator is highly biased. This dampens the evaluator's expected net utility. For a fixed prior, compare, for example, the evaluator's full separation net utility when $\varepsilon_{0}=0$ in Fig. 5a with his partial separation net utility when $\varepsilon_{1}=\frac{1}{10}$ in Fig. 5b: while a highly biased evaluator still finds a blind audition more profitable for this ability composition of the applicant pool and this degree of performance uncertainty, the expected net gain is smaller.

Second, with uncertainty exceeding the threshold, blind auditions are not guaranteed to be more profitable than informed auditions when the evaluator is highly biased (Fig. 6). However, blind auditions are still guaranteed to be more profitable for a sufficiently high prior approximately greater than 0.46 . Intuitively, while the less able participate in the blind audition, the highly biased evaluator can, at least, provide effort incentives for close to the majority of the highly able.

\footnotetext{
23 A different interpretation is that the applicant may be lucky, or have mastered the "inner game" (Gallwey 1974).
} 
Third, full separation insured the highly biased evaluator against negative net utility in a blind audition. With uncertainty above the threshold and partial separation, the evaluator's net utility may be negative for very low priors. In fact, there are biasprior-uncertainty combinations for which neither blind nor informed auditions are profitable. For $\varepsilon_{1}=\frac{1}{10}$, these combinations are the grey-shaded areas in Fig. 6 .

To gain some intuition behind the evaluator's distribution of preferences, suppose that, if the degree of performance uncertainty $\varepsilon_{1}$ is moderate, the evaluator's bias and the prior on high ability are drawn uniformly from their respective supports. Thus, all points in Fig. 6 are equally likely before the three-stage game under performance uncertainty is played. As in Sect. 5, I discount the white areas for which no comparison is possible when calculating the ex-ante percentage with which a blind audition (red area) is preferred relative to an informed audition (blue area), or neither (grey area). The evaluator prefers a blind audition approximately fifty percent and an informed audition approximately forty-five percent of the time. Neither audition is preferred approximately five percent of the time (Fig. 6). First, this highlights the sizeable risk of market failure under performance uncertainty: the evaluator might prefer to not hold an audition at all. Second, this highlights that an informed audition gains only about nine while a blind audition loses about fourteen percentage points in the move from a certain to a moderately uncertain environment. In other words, the evaluator is worse off as the performance uncertainty reduces the attractiveness of a blind audition by more than it increases the attractiveness of an informed audition. Taken together, the welfare loss of asymmetric performance uncertainty comes from the possibility of market failure: the no-audition scenario did not exist under Assumption 4 in Fig. 3. Further, the combination of moderate performance uncertainty with a simple form of heterogeneity in the bias across evaluators as well as in the ability composition of applicant pools may rationalise the co-existence of blind and informed auditions in more equal proportions.

\subsection{Policy recommendations under performance uncertainty}

If performance uncertainty is an inherent feature of the environment and cannot be alleviated, then policy should ensure that the applicant pool is of sufficiently high ability. Examples could be early childhood interventions to identify talent and to build performance excellence gradually via deliberate practice and, thereafter, merit scholarships for formal training to secure a steady influx of highly able musicians into the applicant pool. Direct interventions could target artistic poverty and the necessity for multi-jobbing, often in teaching, to earn a subsistence income as main barriers to human capital investment later in life. One could ask whether "auditioning, networking, keeping fit, practising and unpaid rehearsing [should] be counted as part of the artists' labo[u]r supply" (Towse 1996, p. 102) to reward human capital investment.

Under performance uncertainty, such ability-targeting policy is beneficial for two reasons: first, it guarantees the profitability of the partially separating blind audition when the evaluator is highly biased. Second, it guarantees that blind auditions outperform informed auditions. This may be desirable for equality of opportunity. 


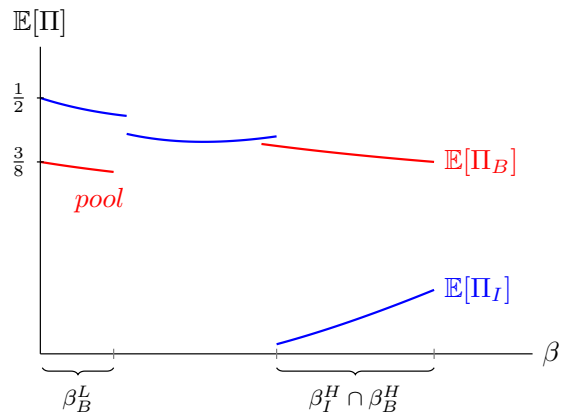

(a) $\operatorname{Pr}\left(\eta_{H}\right)=\frac{1}{2}$ and $\varepsilon_{0}=0$.

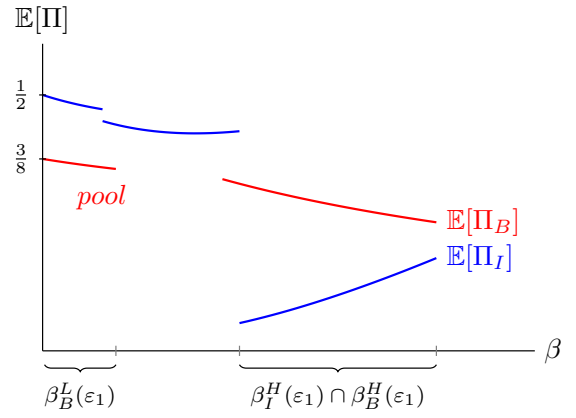

(b) $\operatorname{Pr}\left(\eta_{H}\right)=\frac{1}{2}$ and $\varepsilon_{1}=\frac{1}{10}$.

Fig. 5 Evaluator's expected net utility in a blind and informed audition under performance uncertainty

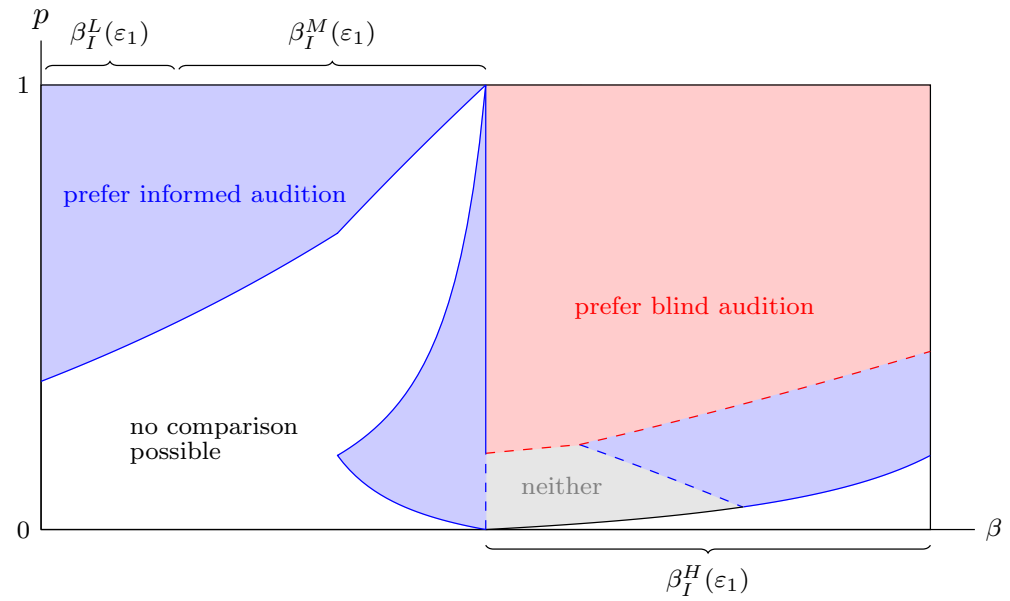

Fig. 6 Evaluator's preferences over auditions for different biases and priors for $\varepsilon_{1}=\frac{1}{10}$

Intuitively, under performance uncertainty, an applicant pool of sufficiently high ability helps counteract that blind auditions only achieve partial separation. Furthermore, it helps avoiding market failure, which may arise if neither informed nor blind auditions are profitable. In this case, it would seem natural for the evaluator to revert to the outside option immediately without holding an audition at all. This would lead to continual subcontracting or zero-hour contracts in the performing arts, reinforcing gender inequality via the difficulty of combining precarious employment with motherhood and caring responsibilities (Conor et al. 2015).

The recommendation for government to stimulate the acquisition of skills is in line with existing research on effective interventions in the presence of low-skill bad-job equilibria (Snower 1994): when there is a small proportion of highly able types, the evaluator has little incentive to fill the position permanently, which, in turn, reinforces the underprovision of skilled labour. Furthermore, a training supply 
externality arises because an increase in the number of high-ability types in the population raises the probability that the evaluator will face and hire a highly able applicant, which raises his expected payoff from holding the audition. There may also be a rationale for speed if market failure leads the intervention to be less effective (Oberholzer-Gee 2008). The policy recommendation to promote efficiency and equity under performance uncertainty finds long-standing empirical support in a number of countries: state-run music conservatoires and departments of music and drama as part of more general educational institutions provide education opportunities. Training orchestras support the professional aspects of the performing arts (Throsby and Withers 1979).

Market failure may have adverse and wide-ranging consequences for welfare beyond gender inequality. One mechanism could be reduced civic engagement. Research by the National Endowment For The Arts (2009) finds that "Americans who create or perform art are more civically active than the general U.S. adult population" (p. 6). A second mechanism could be reduced spillover effects accruing to the neighbourhood in which musicians reside and work. Research by the Social Impact of the Arts Project (2017) at the University of Pennsylvania, School of Social Policy and Practice, finds that cultural resources positively affect a neighbourhood's health and crime rate, and the outcomes of its schools. While this is not a causal relationship, cultural resources, such as artists, are argued to be vital for an environment that promotes social wellbeing.

\section{Blind audition versus affirmative action}

A blind audition serves as a policy to counteract first impression biases. As a measure that eliminates the effect of the evaluator's taste for male applicants on his hiring decision, it creates an environment of equal opportunity for females and males: conditional on ability and performance quality, females and males have the same hiring probability. Yet, government policy often goes further, imposing affirmative action: "any measure, beyond simple termination of a discriminatory practice, adopted to correct or compensate for past or present discrimination or to prevent discrimination from recurring in the future" (U.S. Commission on Civil Rights 1977, p. 2). Examples are reverse discrimination, preferential treatment and quotas. A natural question is, therefore, how blind auditions as an equal opportunity policy compare to these more drastic policies aimed at mitigating biases.

\subsection{Simple quota}

A number of governments impose quotas to increase female representation in the labour market. Since 2006, for example, Norway enforces a previously voluntary quota of 40 percent for the boards of directors of publicly listed companies (Bertrand et al. 2019). In my benchmark model, such a simple quota may be implemented as the constraint that a female applicant is guaranteed to be hired with 
some probability $x \leq \frac{1}{2}$. This puts a floor on the hiring probabilities of females in an informed audition:

$$
\begin{aligned}
& \operatorname{Pr}\left(h \mid q_{L}, \eta_{L}, f\right)=\underline{x}, \\
& \operatorname{Pr}\left(h \mid q_{H}, \eta_{L}, f\right)=\max \left\{\underline{x}, \frac{1}{2+\beta}\right\}, \\
& \operatorname{Pr}\left(h \mid q_{L}, \eta_{H}, f\right)=\max \left\{\underline{x}, \frac{1}{2+\beta}\right\}, \\
& \operatorname{Pr}\left(h \mid q_{H}, \eta_{H}, f\right)=\max \left\{\underline{x}, \frac{2}{2+\beta}\right\}=\frac{2}{2+\beta} \quad \forall \beta \in[0,2) .
\end{aligned}
$$

Specifically, if $x=\frac{4}{10}$, then low-ability females exerting low effort are always hired with this probability; that is, the quota always binds. Furthermore,

$$
\operatorname{Pr}\left(h \mid q_{H}, \eta_{L}, f\right)=\operatorname{Pr}\left(h \mid q_{L}, \eta_{H}, f\right)= \begin{cases}\frac{1}{2+\beta} & \text { if } \beta \leq \frac{1}{2} \\ \frac{4}{10} & \text { otherwise }\end{cases}
$$

As a result, the simple quota affects the participation and incentive compatibility constraints of female applicants. In particular, for low-ability females,

$$
U\left(e_{L}, \eta_{L}, f\right)=\frac{4}{10} w-\frac{1}{2}, \quad U\left(e_{H}, \eta_{L}, f\right)= \begin{cases}\frac{1}{2+\beta} w-2 & \text { if } \beta \leq \frac{1}{2}, \\ \frac{4}{10} w-2 & \text { otherwise }\end{cases}
$$

where $w=\mathbb{E}[\bar{U}]=3-\frac{\beta}{2}$. The quota alters the participation constraint of low-ability females: low effort yields a positive payoff for all biases. High effort, in contrast, always yields a negative payoff. A policy of guaranteeing females a hiring probability of 40 percent, therefore, induces low-ability females to exert low effort for all levels of bias, and forces a loss on the evaluator in this subgame. What is more, a simple quota may go beyond equal opportunity for low-ability females and males; that is, for $\beta<\frac{4}{3}$, it results in reverse discrimination or preferential treatment:

$$
\operatorname{Pr}\left(h \mid q_{L}, \eta_{L}, m\right)=\frac{\beta}{2+\beta}<\frac{4}{10}=\underline{x}=\operatorname{Pr}\left(h \mid q_{L}, \eta_{L}, f\right) \text { if } \beta<\frac{4}{3} .
$$

For high-ability females,

$$
U\left(e_{L}, \eta_{H}, f\right)=\left\{\begin{array}{ll}
\frac{1}{2+\beta} w-\frac{1}{4} & \text { if } \beta \leq \frac{1}{2}, \\
\frac{4}{10} w-\frac{1}{4} & \text { otherwise, }
\end{array} \quad U\left(e_{H}, \eta_{H}, f\right)=\frac{2}{2+\beta} w-1,\right.
$$

where $w=\mathbb{E}[\bar{U}]=3-\frac{\beta}{2}$. The quota alters the incentive compatibility constraint of high-ability females: low effort yields a higher payoff than high effort for biases exceeding $\frac{51-\sqrt{1929}}{8} \approx 0.89$. As a result, the threshold bias beyond which effort incentives for a highly able female are distorted is lower. For moderate biases, $\beta \in\left(\frac{51-\sqrt{1929}}{8}, \frac{6}{5}\right]$, the quota, thus, has unintended consequences: highly able 
females are hired less often due to the quota's effect on effort incentives. Moreover, this hiring probability is precisely the quota for such moderate biases (Fig. 7).

In consequence, simple quotas cannot provide equal opportunity and targeted effort incentives in my benchmark model. Moreover, my results echo the findings of Coate and Loury (1993) and Moro and Norman (2003) in that quotas can hurt the intended beneficiaries. In my setting, the quota causes the hiring probability of highly able females to fall for a moderate range of biases before it achieves its aim of putting a floor on the hiring probability for higher biases.

\subsection{Beyond simple quotas}

Simple quotas are not sufficient for equal opportunity and targeted effort incentives when they affect the behaviour of the target group and, as a consequence, the behaviour of the evaluator. An alternative is to force the evaluator to hire females a priori (across subgames) with some probability $\underline{x}$. The evaluator then has discretion to adjust the hiring probabilities within subgame $\left(\eta_{L}, f\right)$ and $\left(\eta_{H}, f\right)$ to provide targeted effort incentives. In particular, to avoid attracting low-ability females, he can hire exclusively highly able females more often than demanded by the hiring rule (3) in order to fulfil the quota. Given effort responses in stage 2, the probability of hiring female applicants across subgames is

$$
\operatorname{Pr}(h \mid f)= \begin{cases}\frac{2 p}{2+\beta} & \text { if } \beta \leq \frac{6}{5}, \\ \frac{p}{2+\beta} & \text { otherwise. }\end{cases}
$$

For low biases, therefore, the quota is binding if $\underline{x}>\frac{2 p}{2+\beta}$. For example, when $\underline{x}=\frac{4}{10}$ and $p=\frac{1}{2}$, the quota is binding for biases exceeding one-half, and the evaluator is forced to hire highly able females with probability $x / p$ in subgame $\left(\eta_{H}, f\right)$ to fulfil the quota. As a corollary, such a quota is only feasible if it does not exceed the prior that the applicant is of high ability.

\subsection{Employment subsidy}

An alternative practice is to pay subsidies to firms who employ a certain type of worker (e.g. Card et al. 2010, 2017). In my benchmark model, this may be implemented as a subsidy of at most $\beta$ conditional on hiring a female applicant in the audition. The outside option remains unchanged; that is, the evaluator does not receive the employment subsidy if he hires a substitute that turns out to be a female. The evaluator's gross utility (1) changes to

$$
V(q, \eta, g)+\alpha \beta g=f(q, \eta)-(1-\alpha) \beta g,
$$

where $\alpha=1$ represents a full employment subsidy. Given the altered gross utility and no change in the outside option, as $\alpha \uparrow 1$, the conditional hiring probabilities of females approach the ones of males. In fact, under a full subsidy, if $\beta \in \beta_{I}^{L}$, only high-ability applicants participate and exert high effort. If $\beta \in \beta_{I}^{M}$, low-ability 
Fig. 7 Effect of a simple quota on the hiring probability of a high-ability female via her effort response

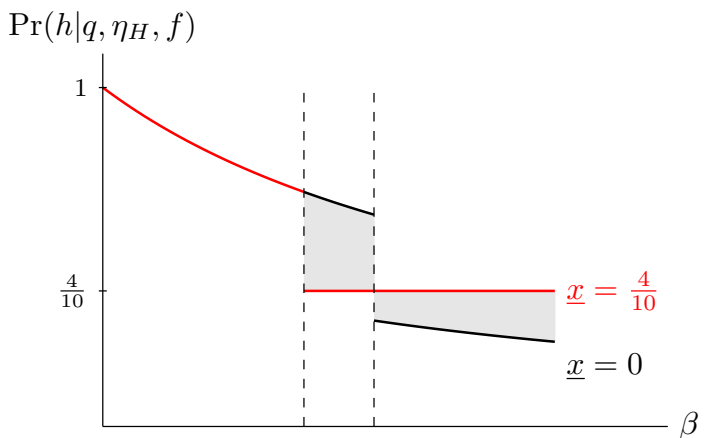

applicants also participate and exert low effort. If $\beta \in \beta_{I}^{H}$, all applicants participate and exert low effort. For low biases, the full employment subsidy can, therefore, achieve both targeted effort incentives and equal opportunity. For moderate and high biases, equal opportunity is achieved at the expense of attracting low-ability females and males alike.

\section{Agency cost}

Equal opportunity and efficiency are commonly argued to be conflicting policy objectives (e.g. Sowell 2004). To analyse whether this trade-off arises under tastebased discrimination, I measure efficiency through the evaluator's agency cost in the two audition forms. ${ }^{24}$ In particular, for a given bias, this agency cost is the difference between the evaluator's hypothetical payoff when only highly able applicants participate and exert high effort in the audition form and the evaluator's actual expected net utility. In an informed audition, the hypothetical payoff is derived from extrapolating $\mathbb{E}\left[\Pi_{I} \mid \beta \in \beta_{I}^{L}\right]$ to higher biases. In a blind audition, the hypothetical payoff is derived from extrapolating $\mathbb{E}\left[\Pi_{B} \mid \beta \in \beta_{B}^{H}\right]$ to lower biases in the absence of performance uncertainty. ${ }^{25}$

In the absence of performance uncertainty, if the evaluator's bias against female applicants is low, the agency cost is zero in an informed audition due to targeted effort incentives. In contrast, when the bias is moderate, there is an agency cost from attracting low-ability males who exert low effort. When highly biased, the agency cost increases further due to the provision of low rather than high effort incentives for highly able applicants. In a blind audition, the agency cost is zero if the evaluator's bias is high. Conversely, when the bias is low, an agency cost arises from

\footnotetext{
${ }^{24}$ In the literature, agency cost is defined as the sum of the principal's monitoring expenditures, the bonding expenditures by the agent, and the residual loss that arises from a divergence between the agent's decisions and those decisions which would maximise the principal's welfare (Jensen and Meckling 1976). In my model, the agency cost is purely driven by the residual loss arising from distorted effort incentives.

${ }^{25}$ A formal definition of agency cost and a formal statement of this section's results is in the working paper.
} 
attracting also low-ability applicants who exert high effort. Figure 8a depicts the agency cost (AC) in both audition forms for a prior of one-half.

Consequently, above a certain threshold bias, a blind audition is an efficient mechanism to screen applicants by ability and to provide targeted effort incentives. What is more, equal opportunity and targeted effort incentives are complementary objectives: there is no trade-off between implementing blind auditions as a policy to counteract first impression biases and efficiency due to adverse effects on targeted effort provision. For a low bias, in contrast, an informed audition poses an efficient mechanism. In this case, equal opportunity and targeted effort incentives are conflicting objectives: while blind auditions serve as a policy to counteract biases, they may lead to an avalanche of applicants and efficiency loss as unintended consequences.

Under asymmetric performance uncertainty, however, a blind audition no longer poses an efficient mechanism: partial separation leads to a positive agency cost for a highly biased evaluator (Fig. 8b). Given that this agency cost is decreasing in the prior, ability-targeting interventions reduce the inefficiency. The agency cost in an informed audition for a moderate and high bias is lower relative to certainty. Intuitively, the evaluator prefers to hire an applicant who delivers a high-quality performance. Under certainty, this objective coincides with the provision of high effort incentives. Under performance uncertainty, this is no longer the case and the agency cost from a low effort decision is reduced due to the possibility that low effort still results in a high-quality performance. Due to the asymmetry in Assumption 5, the agency cost in the high-effort pooling equilibrium remains unchanged.

\section{Gender-blind curriculum vitae}

In my model, concealing the applicant's gender necessitates concealing the applicant's ability. Even with such a trade-off, I show that a blind audition can be optimal for the evaluator. Yet, with advanced technology and software able to edit out selected pieces of information on a $\mathrm{CV}$, the evaluator could design the blind audition: he may choose to neither learn ability nor gender, or ask for a gender-blind CV that contains valuable information about ability.

Therefore, an important question for policy is whether a gender-blind CV coupled with a blindfolded performance can serve as an improved equal opportunity policy. In other words, if the evaluator was bound to hold a blind audition to create an environment of equal opportunity, would he prefer to see a gender-blind CV prior to the blindfolded performance? ${ }^{26}$ If the evaluator decides to obtain information about ability beforehand, he preempts signalling: given a gender-blind CV, low-ability applicants cannot pool with the highly able in the blind audition. ${ }^{27}$

\footnotetext{
26 A formal statement of this section's results is in the working paper.

27 As before, gender cannot be signalled so that the evaluator will always believe the applicant to be a female or a male with equal probability.
} 




(a) $\operatorname{Pr}\left(\eta_{H}\right)=0.5$ and $\varepsilon_{0}=0$.

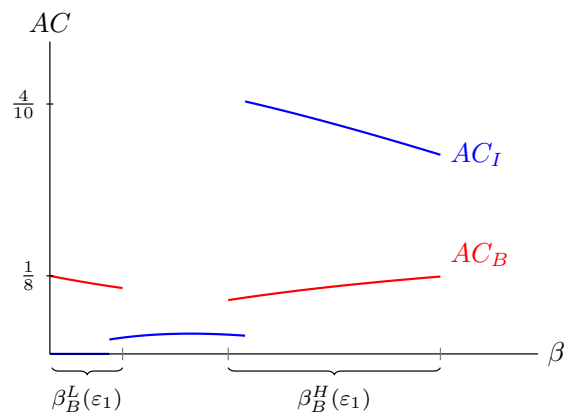

(b) $\operatorname{Pr}\left(\eta_{H}\right)=0.5$ and $\varepsilon_{1}=\frac{1}{10}$.

Fig. 8 Agency cost in a blind and informed audition

The submission of a gender-blind CV prior to the blindfolded performance motivates highly able applicants to exert high effort for biases below a certain threshold. Further, low-ability applicants never participate when the evaluator requires a gender-blind CV. Consequently, for low biases, a blind audition coupled with a gender-blind $\mathrm{CV}$ does not have the unintended consequences of a blind audition that conceals both gender and ability.

The addition of gender-blind CVs to a blind audition reverses the results in Lemma 3: a blind audition without any form of CV provides targeted effort incentives for high biases; a blind audition with gender-blind CVs provides targeted effort incentives for low biases. Thus, if the evaluator was bound to hold a blind audition for equal opportunity, he would choose to see a gender-blind CV for a low bias, $\left.\beta \in \beta_{B}^{L}\right|_{p \uparrow 1}$. He would be indifferent for a moderate bias, $\beta \in \beta_{L}^{G} \cap \beta_{B}^{H}$. For a high bias, $\beta \in \beta_{H}^{G}$, he would choose not to see a $\mathrm{CV}$ in any form. A highly biased evaluator takes advantage of the need to signal ability in a blind audition without any form of $\mathrm{CV}$ : the belief that a low-quality performance comes from a less able applicant motivates the highly able to exert high effort.

Given an optimally designed blind audition, I can compare the evaluator's expected net utility across the blind and informed audition for essentially all biasprior combinations (Fig. 9a). If the evaluator's bias against female applicants is low, he prefers an informed audition over a blind audition with ability revealed. For high biases, the evaluator prefers a blind audition with ability concealed over an informed audition. For moderate biases, the prior about ability determines whether the evaluator prefers an informed or a blind audition with ability revealed through genderblind CVs. Consequently, Proposition 4 is robust to the introduction of audition design in stage 1. Further, the evaluator's distribution of preferences is similar if he can design the blind audition: the optimally designed blind audition is preferred approximately sixty-two percent of the time. These insights extend to performance uncertainty when a blind audition with ability concealed cannot provide targeted effort incentives (Fig. 9b). 


\section{Conclusion}

In this paper, I developed a game-theoretic framework in which the evaluator is biased against females and his bias is common knowledge. I showed that, above a threshold bias, the evaluator prefers a blind audition to provide high effort incentives exclusively for high-ability applicants. I also showed that a highly biased evaluator's preferences align with those of a highly able female. The introduction of performance uncertainty may lead to market failure or may render informed auditions more profitable, rationalising ability-targeting interventions. While a full employment subsidy can be a viable alternative to a blind audition for low biases, a simple quota cannot provide equal opportunity and targeted effort incentives in my benchmark model. Finally, I showed that it can be optimal to reveal ability through a gender-blind CV.

My paper opens up intriguing avenues to study in more depth the potential trade-off between policies mitigating biases and effort incentives for applicants. In Sect. 7, I have taken a first look at quotas and subsidies. Another example is a setting in which the evaluator's bias is not common knowledge: what if applicants are uncertain or underestimate the evaluator's bias? Specifically, applicants perceiving their identity more strongly may attend to the evaluator's bias more (Antecol and Cobb-Clark 2008). What if the evaluator is partially sophisticated or naive about his bias when choosing the audition form? This enquiry is motivated by evidence that many forms of bias work at a subconscious level; for example, via a vision heuristic (Footnote 8). Few studies examine the implications of competition among applicants, allowing for potentially more complex biases in an informed audition (Page and Page 2010). A first point of departure may be a tournament model à la Cornell and Welch (1996). Another promising avenue is to microfound the evaluator's bias; for example, via a categorical model of cognition (Fryer and Jackson 2008). Finally, future research could consider situations in which deliberate practice does not allow an applicant to deliver a high-quality performance with certainty; overlearning and overpreparation could arguably make an applicant more adept at responding to factors outside of her control. 


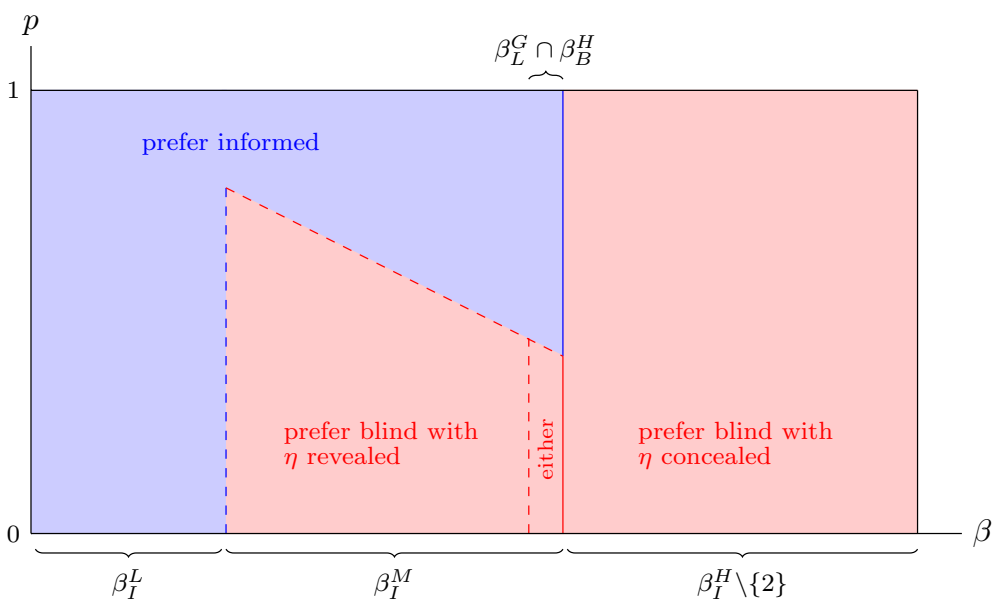

(a) $\varepsilon_{0}=0$

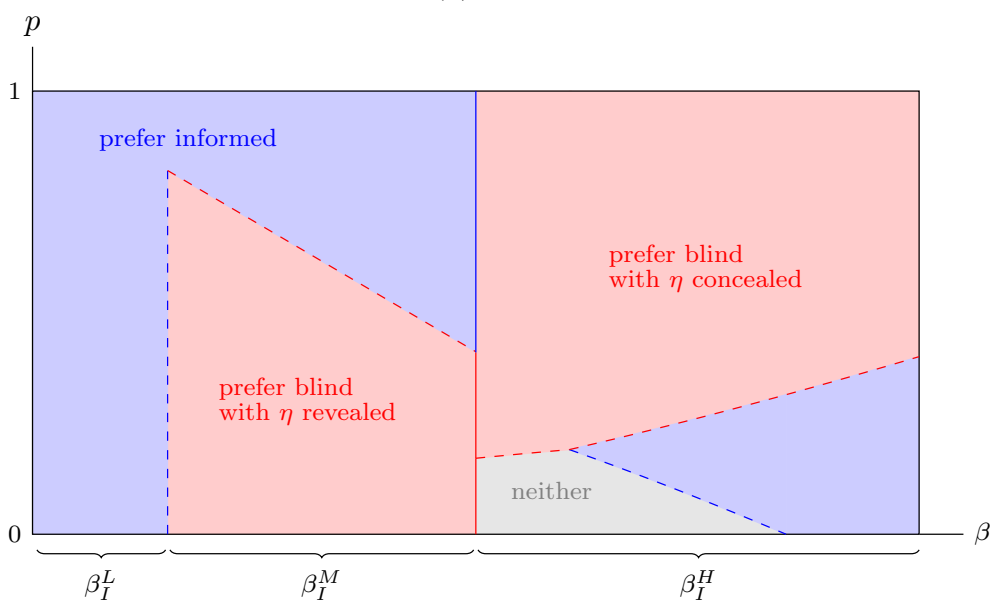

(b) $\varepsilon_{1}=\frac{1}{10}$

Fig. 9 The effect of gender-blind CVs on the evaluator's preferences over auditions 


\section{Appendices}

\section{Proofs}

Proof of Lemma 1 First, note that substituting for the hiring probabilities in equation (2) yield

$$
\begin{aligned}
U\left(e_{L}, \eta_{L}, f\right) & =-\frac{1}{2}, & U\left(e_{L}, \eta_{L}, m\right) & =\frac{\beta}{2+\beta} w-\frac{1}{2}, \\
U\left(e_{H}, \eta_{L}, f\right) & =\frac{1}{2+\beta} w-2, & U\left(e_{H}, \eta_{L}, m\right) & =\frac{1+\beta}{2+\beta} w-2, \\
U\left(e_{L}, \eta_{H}, f\right) & =\frac{1}{2+\beta} w-\frac{1}{4}, & U\left(e_{L}, \eta_{H}, m\right) & =\frac{1+\beta}{2+\beta} w-\frac{1}{4}, \\
U\left(e_{H}, \eta_{H}, f\right) & =\frac{2}{2+\beta} w-1, & U\left(e_{H}, \eta_{H}, m\right) & =w-1
\end{aligned}
$$

in an informed audition, where by Assumption 3 an applicant's wage is $w=\mathbb{E}[\bar{U}]=3-\frac{\beta}{2}$.

Low-ability females drop out of the audition for all possible biases (Fig. 10a). High-ability females exert high effort if $\beta \in\left[0, \frac{6}{5}\right]$ and low effort if $\beta \in\left(\frac{6}{5}, 2\right]$ (Fig. 10b). Low-ability males drop out if $\beta$ is strictly lower than $\frac{5-\sqrt{17}}{2}$, and exert low effort if $\beta \in\left[\frac{5-\sqrt{17}}{2}, 2\right]$ (Fig. 10c). High-ability males exert high effort if $\beta \in\left[0, \frac{6}{5}\right]$ and low effort if $\beta \in\left(\frac{6}{5}, 2\right]$ (Fig. 10d). Note the gender differences for low-ability applicants: $U\left(e_{L}, \eta_{L}, m\right)$ is increasing in the evaluator's bias while $U\left(e_{L}, \eta_{L}, f\right)$ is negative and independent of the bias.

Proof of Proposition 1 To derive the evaluator's expected net utility when his bias is low, moderate, or high, I first determine his gross utility in each of the four possible subgames. Using the fact that subgames $\left(\eta_{L}, f\right)$ and $\left(\eta_{L}, m\right)$ are each reached with probability $(1-p) / 2$ whilst $\left(\eta_{H}, f\right)$ and $\left(\eta_{H}, m\right)$ are each reached with probability $p / 2$, I then derive the evaluator's overall expected gross utility in stage 1 . Only in the last step, I subtract wage costs as $w:=w_{\theta}=w_{\bar{U}}$ for all $\theta \in \Theta$ by Assumption 3 .

Suppose the evaluator's bias against female applicants is low; that is, $\beta \in \beta_{I}^{L}$ where $\beta_{I}^{L}$ is defined as in Lemma 1(i). Then, low-ability males and females do not participate and high-ability males and females exert high effort. In subgame $\left(\eta_{L}, f\right)$ and $\left(\eta_{L}, m\right)$, the evaluator, therefore, hires the outside option with probability one. With a slight abuse of notation, the evaluator's expected gross utility is the expected value of the outside option:

$$
\mathbb{E}\left[V \mid O, \eta_{L}, f\right]=\mathbb{E}\left[V \mid O, \eta_{L}, m\right]=\mathbb{E}[\bar{U}]=3-\frac{\beta}{2} .
$$






(a) Low-ability female.

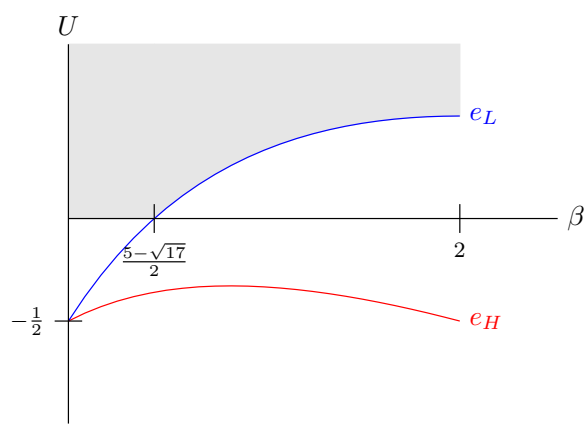

(c) Low-ability male.

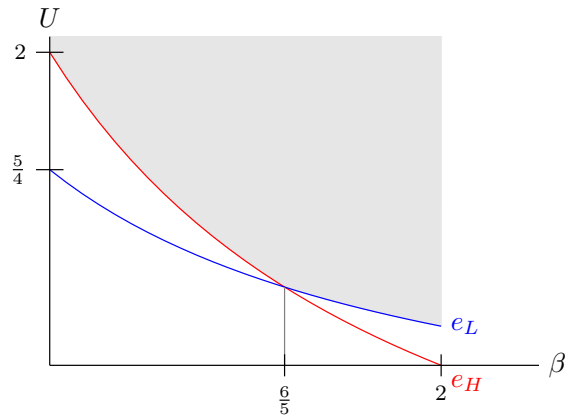

(b) High-ability female.

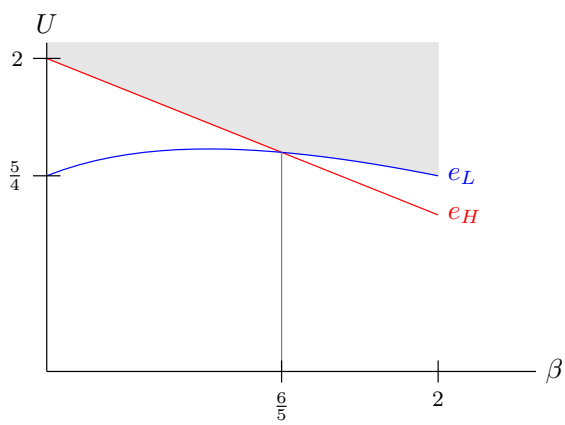

(d) High-ability male.

Fig. 10 Effort choices in an informed audition

As $w=\mathbb{E}[\bar{U}]$, the evaluator, by construction, breaks even after accounting for wage costs in these two subgames. In subgame $\left(\eta_{H}, f\right)$, the evaluator's gross utility from hiring the applicant is $4-\beta$ with corresponding hiring probability $\frac{2}{2+\beta}$. The evaluator hires the outside option with expected value $3-\frac{\beta}{2}$ with complementary probability $\frac{\beta}{2+\beta}$. The evaluator's expected gross utility in subgame $\left(\eta_{H}, f\right)$ can then be calculated as the probability that he hires the applicant times the utility from hiring her plus the probability that he hires the outside option times the expected value of the outside option: ${ }^{28}$

$$
\begin{aligned}
\mathbb{E}\left[V \mid q_{H}, \eta_{H}, f\right] & =\operatorname{Pr}\left(h \mid q_{H}, \eta_{H}, f\right) V\left(q_{H}, \eta_{H}, f\right)+\left[1-\operatorname{Pr}\left(h \mid q_{H}, \eta_{H}, f\right)\right] \mathbb{E}[\bar{U}], \\
& =\frac{2}{2+\beta}(4-\beta)+\frac{\beta}{2+\beta}\left(3-\frac{\beta}{2}\right)=2-\frac{\beta}{2}+\frac{4}{2+\beta} .
\end{aligned}
$$

\footnotetext{
$\overline{{ }^{28}}$ Recall that, by Assumption 2, the value of $\bar{U}$ is unknown to the evaluator when making the hiring decision. Therefore, all calculations use the unconditional expected value of the outside option. The model's results are robust to altering the timing and using the conditional expected value. However, when engaging a substitute from an agency, it is more appropriately interpreted as a gamble as done here.
} 
In subgame $\left(\eta_{H}, m\right)$, the evaluator's gross utility from hiring the applicant is 4 with corresponding hiring probability 1 . His expected gross utility in this subgame, therefore, is

$$
\mathbb{E}\left[V \mid q_{H}, \eta_{H}, m\right]=\operatorname{Pr}\left(h \mid q_{H}, \eta_{H}, m\right) V\left(q_{H}, \eta_{H}, m\right)=4 .
$$

Under the common prior assumption, the evaluator's overall expected gross utility in stage 1 in an informed audition is

$$
\begin{aligned}
\mathbb{E}[V \mid \beta]= & \frac{1-p}{2}\left[\mathbb{E}\left[V \mid O, \eta_{L}, f\right]+\mathbb{E}\left[V \mid O, \eta_{L}, m\right]\right] \\
& +\frac{p}{2}\left[\mathbb{E}\left[V \mid q_{H}, \eta_{H}, f\right]+\mathbb{E}\left[V \mid q_{H}, \eta_{H}, m\right]\right], \\
= & \frac{1-p}{2}\left[\left(3-\frac{\beta}{2}\right)+\left(3-\frac{\beta}{2}\right)\right]+\frac{p}{2}\left[\left(2-\frac{\beta}{2}+\frac{4}{2+\beta}\right)+4\right] .
\end{aligned}
$$

After subtracting wage costs, the evaluator's expected net utility is

$$
\mathbb{E}\left[\Pi_{I} \mid \beta \in \beta_{I}^{L}\right]:=\mathbb{E}\left[V \mid \beta \in \beta_{I}^{L}\right]-w=\frac{p}{2}\left[\frac{2}{2+\beta}\left(1-\frac{\beta}{2}\right)+\left(1+\frac{\beta}{2}\right)\right]>0 .
$$

Suppose the evaluator is moderately biased against female applicants; that is, $\beta \in \beta_{I}^{M}$ where $\beta_{I}^{M}$ is defined as in Lemma 1(ii). Then, subgame $\left(\eta_{L}, f\right),\left(\eta_{H}, f\right)$ and $\left(\eta_{H}, m\right)$ remain unchanged. Low-ability males participate and exert low effort. The evaluator's gross utility from hiring the applicant in subgame (c) changes to 2 with corresponding hiring probability $\frac{\beta}{2+\beta}$. The evaluator hires the outside option with expected value $3-\frac{\beta}{2}$ with complementary probability $\frac{2}{2+\beta}$. The evaluator's expected gross utility in subgame $\left(\eta_{L}, m\right)$, therefore, becomes

$$
\begin{aligned}
\mathbb{E}\left[V \mid q_{L}, \eta_{L}, m\right] & =\operatorname{Pr}\left(h \mid q_{L}, \eta_{L}, m\right) V\left(q_{L}, \eta_{L}, m\right)+\left[1-\operatorname{Pr}\left(h \mid q_{L}, \eta_{L}, m\right)\right] \mathbb{E}[\bar{U}], \\
& =\frac{\beta}{2+\beta} 2+\frac{2}{2+\beta}\left(3-\frac{\beta}{2}\right)=1+\frac{4}{2+\beta},
\end{aligned}
$$

which is strictly less than $\mathbb{E}[\bar{U}]$ for all $\beta$. Because $w=\mathbb{E}[\bar{U}]$, the evaluator's expected utility net of wage costs is, thus, negative in subgame $\left(\eta_{L}, m\right)$ when he is moderately biased. The evaluator's overall expected gross utility becomes

$$
\begin{aligned}
\mathbb{E}\left[V \mid \beta \in \beta_{I}^{M}\right]= & \frac{1-p}{2}\left[\mathbb{E}\left[V \mid O, \eta_{L}, f\right]+\mathbb{E}\left[V \mid q_{L}, \eta_{L}, m\right]\right] \\
& +\frac{p}{2}\left[\mathbb{E}\left[V \mid q_{H}, \eta_{H}, f\right]+\mathbb{E}\left[V \mid q_{H}, \eta_{H}, m\right]\right], \\
= & \frac{1-p}{2}\left[\left(3-\frac{\beta}{2}\right)+\left(1+\frac{4}{2+\beta}\right)\right]+\frac{p}{2}\left[\left(2-\frac{\beta}{2}+\frac{2}{2+\beta}\right)+4\right] .
\end{aligned}
$$

After subtracting wage costs, the evaluator's expected net utility is 


$$
\begin{aligned}
\mathbb{E}\left[\Pi_{I} \mid \beta \in \beta_{I}^{M}\right] & :=\mathbb{E}\left[V \mid \beta \in \beta_{I}^{M}\right]-w, \\
& =\frac{1-p}{2}\left[\frac{\beta}{2+\beta}\left(\frac{\beta}{2}-1\right)\right]+\frac{p}{2}\left[\frac{2}{2+\beta}\left(1-\frac{\beta}{2}\right)+\left(1+\frac{\beta}{2}\right)\right] \gtrless 0 .
\end{aligned}
$$

Suppose the evaluator is highly biased against female applicants; that is, $\beta \in \beta_{I}^{H}$ where $\beta_{I}^{H}$ is defined as in Lemma 1 (iii). Then, subgame $\left(\eta_{L}, f\right)$ and $\left(\eta_{L}, m\right)$ remain unchanged. High-ability females and males exert low effort. The evaluator's gross utility from hiring the applicant in subgame $\left(\eta_{H}, f\right)$ changes to $3-\beta$ with corresponding hiring probability $\frac{1}{2+\beta}$. The evaluator hires the outside option with expected value $3-\frac{\beta}{2}$ with complementary probability $\frac{1+\beta}{2+\beta}$. The evaluator's expected gross utility in subgame $\left(\eta_{H}, f\right)$, therefore, falls to

$$
\begin{aligned}
\mathbb{E}\left[V \mid q_{L}, \eta_{H}, f\right] & =\operatorname{Pr}\left(h \mid q_{L}, \eta_{H}, f\right) V\left(q_{L}, \eta_{H}, f\right)+\left[1-\operatorname{Pr}\left(h \mid q_{L}, \eta_{H}, f\right)\right] \mathbb{E}[\bar{U}], \\
& =\frac{1}{2+\beta}(3-\beta)+\frac{1+\beta}{2+\beta}\left(3-\frac{\beta}{2}\right)=\frac{5}{2}-\frac{\beta}{2}+\frac{1}{2+\beta}
\end{aligned}
$$

The evaluator's gross utility from hiring the applicant in subgame $\left(\eta_{H}, m\right)$ changes to 3 with corresponding hiring probability $\frac{1+\beta}{2+\beta}$. The evaluator hires the outside option with expected value $3-\frac{\beta}{2}$ with complementary probability $\frac{1}{2+\beta}$. The evaluator's expected gross utility in subgame $\left(\eta_{H}, m\right)$, therefore, falls to

$$
\begin{aligned}
\mathbb{E}\left[V \mid q_{L}, \eta_{H}, m\right] & =\operatorname{Pr}\left(h \mid q_{L}, \eta_{H}, m\right) V\left(q_{L}, \eta_{H}, m\right)+\left[1-\operatorname{Pr}\left(h \mid q_{L}, \eta_{H}, m\right)\right] \mathbb{E}[\bar{U}], \\
& =\frac{1+\beta}{2+\beta} 3+\frac{1}{2+\beta}\left(3-\frac{\beta}{2}\right)=\frac{5}{2}+\frac{1}{2+\beta} .
\end{aligned}
$$

The evaluator's overall expected gross utility becomes

$$
\begin{aligned}
\mathbb{E}\left[V \mid \beta \in \beta_{I}^{H}\right]= & \frac{1-p}{2}\left[\mathbb{E}\left[V \mid O, \eta_{L}, f\right]+\mathbb{E}\left[V \mid q_{L}, \eta_{L}, m\right]\right] \\
& +\frac{p}{2}\left[\mathbb{E}\left[V \mid q_{L}, \eta_{H}, f\right]+\mathbb{E}\left[V \mid q_{L}, \eta_{H}, m\right]\right] \\
= & \frac{1-p}{2}\left[\left(3-\frac{\beta}{2}\right)+\left(1+\frac{4}{2+\beta}\right)\right] \\
& +\frac{p}{2}\left[\left(\frac{5}{2}-\frac{\beta}{2}+\frac{1}{2+\beta}\right)+\left(\frac{5}{2}+\frac{1}{2+\beta}\right)\right]
\end{aligned}
$$

After subtracting wage costs, the evaluator's expected net utility is

$$
\begin{aligned}
\mathbb{E}\left[\Pi_{I} \mid \beta \in \beta_{I}^{H}\right] & :=\mathbb{E}\left[V \mid \beta \in \beta_{I}^{H}\right]-w, \\
& =\frac{1-p}{2}\left[\frac{\beta}{2+\beta}\left(\frac{\beta}{2}-1\right)\right]+\frac{p}{2}\left[\frac{1}{2+\beta}\left(-\frac{\beta}{2}\right)+\frac{1+\beta}{2+\beta}\left(\frac{\beta}{2}\right)\right] \gtrless 0 .
\end{aligned}
$$


Proof of Lemma 2 First, note that substituting for the two hiring probabilities in equation (2) yield

$$
\begin{array}{ll}
U\left(e_{L}, \eta_{L}\right)=\frac{\beta}{4+2 \beta} w-\frac{1}{2}, & U\left(e_{H}, \eta_{L}\right)=\frac{2(1+p)+\beta}{4+2 \beta} w-2, \\
U\left(e_{L}, \eta_{H}\right)=\frac{\beta}{4+2 \beta} w-\frac{1}{4}, & U\left(e_{H}, \eta_{H}\right)=\frac{2(1+p)+\beta}{4+2 \beta} w-1
\end{array}
$$

for both female and male applicants in a pooling blind audition, where $w=\mathbb{E}[\bar{U}]=3-\frac{\beta}{2}$.

(i) For $p<\frac{1}{3}$, I show that $U\left(e_{H}, \eta_{L}\right)$ is strictly negative for all possible values of $\beta$. It is always better for low-ability applicants to not participate. First, note that $U\left(e_{H}, \eta_{L}\right)$ is strictly decreasing in $\beta$ :

$$
\frac{\partial U\left(e_{H}, \eta_{L}\right)}{\partial \beta}=-\frac{4 p}{(4+2 \beta)^{2}}\left(3-\frac{\beta}{2}\right)-\frac{2(1+p)+\beta}{8+4 \beta}<0 \forall \beta \in[0,2] .
$$

This implies that, if $U\left(e_{H}, \eta_{L}\right)<0$ at $\beta=0$, then $U\left(e_{H}, \eta_{L}\right)<0$ for all $\beta \in[0,2]$. I can use this condition to solve for the corresponding prior:

$$
\begin{aligned}
\left.U\left(e_{H}, \eta_{L}\right)\right|_{\beta=0}=\frac{1+p}{2} & 3-2<0, \\
\Rightarrow p & <\frac{1}{3} .
\end{aligned}
$$

Thus, for $p<\frac{1}{3}$, pooling on high effort is never possible.

(ii) For $p=\frac{1}{3}, U\left(e_{H}, \eta_{L}\right)=0$ at $\beta=0$. By the previous argument, $U\left(e_{H}, \eta_{L}\right)<0$ for all $\beta \in(0,2]$. This implies that low-ability applicants are indifferent between exerting high effort and not participating only if the evaluator is unbiased. Furthermore, it is optimal for high-ability applicants to exert high effort whenever it is optimal for low-ability applicants to exert high effort. This is because $U\left(e_{L}, \cdot\right)$ shifts up by $\frac{1}{4}$ while $U\left(e_{H}, \cdot\right)$ shifts up by 1 in the move from $\eta_{L}$ to $\eta_{H}$ (Fig. $11 \mathrm{a}, \mathrm{b}$, respectively). Thus, pooling on high effort is possible at $p=\frac{1}{3}$ if $\beta=0$.

(iii) For $\frac{1}{3}<p<1$, there exists a range of biases for which $U\left(e_{H}, \eta_{L}\right)$ is positive. The upper bound on $\beta$ for which a pooling equilibrium can be supported is determined by the indifference condition

$$
U\left(e_{H}, \eta_{L}\right)=\frac{2(1+p)+\beta}{4+2 \beta}\left(3-\frac{\beta}{2}\right)-2=0 .
$$

Given that $\beta \in[0,2]$, the above equation is uniquely solved by $\beta(p):=\sqrt{p^{2}+16 p}-p-2$. The upper bound $\beta(p)$ is strictly increasing in $p$ :

$$
\frac{d \beta(p)}{d p}=\frac{p+8}{\sqrt{p(p+16)}}-1>0 \forall 0<p<1 .
$$

Taking the limit of $\beta(p)$ yields 


$$
\lim _{p \uparrow 1} \beta(p)=\sqrt{17}-3>0
$$

Proof of Proposition 2 Suppose the evaluator's bias against female applicants is low; that is, $\beta \in \beta_{B}^{L}$ with $\frac{1}{3} \leq p<1$ where $\beta_{B}^{L}$ is defined as in Lemma 2. His expected utility from hiring the applicant at the information set $q_{H}$ is $3+p-\frac{\beta}{2}$ with corresponding hiring probability $\frac{2(1+p)+\beta}{4+2 \beta}$. The evaluator hires the outside option with expected value $3-\frac{\beta}{2}$ with complementary probability $\frac{2(1-p)+\beta}{4+2 \beta}$. Given the evaluator's beliefs, his overall expected gross utility in stage 1 in a pooling blind audition is

$$
\begin{aligned}
\mathbb{E}\left[V \mid \beta \in \beta_{B}^{L}\right] & =\operatorname{Pr}\left(h \mid q_{H}\right) \mathbb{E}\left[V \mid q_{H}\right]+\left[1-\operatorname{Pr}\left(h \mid q_{H}\right)\right] \mathbb{E}[\bar{U}], \\
& =\frac{2(1+p)+\beta}{4+2 \beta}\left(3+p-\frac{\beta}{2}\right)+\frac{2(1-p)+\beta}{4+2 \beta}\left(3-\frac{\beta}{2}\right) .
\end{aligned}
$$

After subtracting wage costs, the evaluator's expected net utility is

$$
\begin{aligned}
\mathbb{E}\left[\Pi_{B} \mid \beta \in \beta_{B}^{L}\right] & :=\mathbb{E}\left[V \mid \beta \in \beta_{B}^{L}\right]-w, \\
& =\frac{2(1+p)+\beta}{4+2 \beta}\left[3+p-\frac{\beta}{2}-\left(3-\frac{\beta}{2}\right)\right]=p \frac{2(1+p)+\beta}{4+2 \beta}>0 .
\end{aligned}
$$

Proof of Lemma 3 First, note that substituting for the two hiring probabilities in the applicant's expected utility (2) yield

$$
\begin{aligned}
& U\left(e_{L}, \eta_{L}\right)=\frac{\beta}{4+2 \beta} w-\frac{1}{2}, \quad U\left(e_{H}, \eta_{L}\right)=\frac{4+\beta}{4+2 \beta} w-2, \\
& U\left(e_{L}, \eta_{H}\right)=\frac{\beta}{4+2 \beta} w-\frac{1}{4}, \quad U\left(e_{H}, \eta_{H}\right)=\frac{4+\beta}{4+2 \beta} w-1
\end{aligned}
$$

for both male and female applicants in a separating blind audition, where $w=\mathbb{E}[\bar{U}]=3-\frac{\beta}{2}$.

For $\beta \in[0, \sqrt{17}-3]$, low-ability applicants exert high effort (Fig. 12a). For $\beta \in(\sqrt{17}-3,2)$, low-ability applicants do not participate in the audition (Fig. 12a). For $\beta \in[0,2]$, high-ability applicants exert high effort in the audition (Fig. 12b).

Proof of Proposition 3 Suppose the evaluator's bias against female applicants is high; that is $\beta \in \beta_{B}^{H}$ where $\beta_{B}^{H}$ is defined as in Lemma 3. The evaluator's expected utility from hiring the applicant at the information set $q_{H}$ is $4-\frac{\beta}{2}$ with corresponding hiring probability $\frac{4+\beta}{4+2 \beta}$. The evaluator hires the outside option with expected value $3-\frac{\beta}{2}$ with complementary probability $\frac{\beta}{2+\beta}$. If the applicant is a low-ability male or female, the evaluator hires the outside option with probability one as those types do not participate. In this case, the evaluator's expected utility is the expected value of the outside option: 


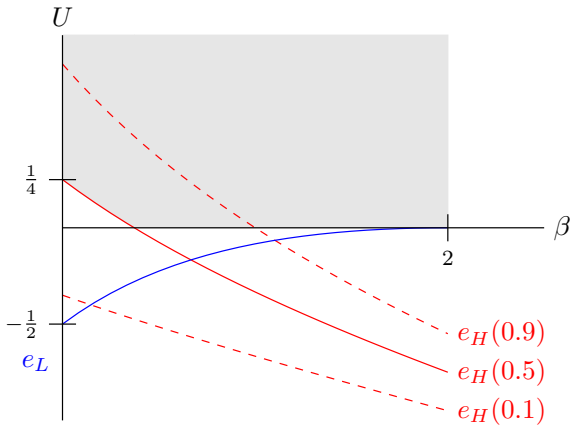

(a) Low-ability applicant.

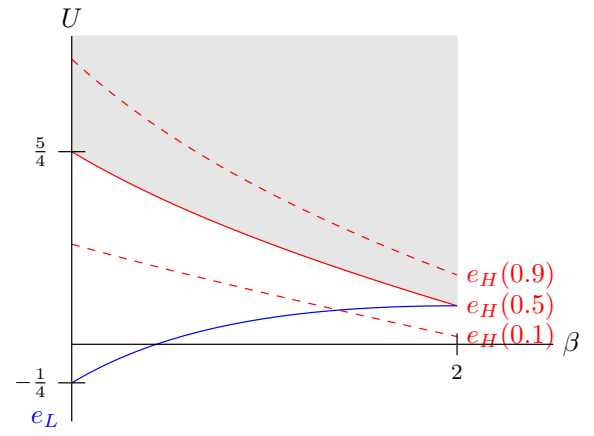

(b) High-ability applicant.

Fig. 11 Effort choices in a pooling blind audition for different priors

$$
\mathbb{E}[V \mid O]=\mathbb{E}[\bar{U}]=3-\frac{\beta}{2} .
$$

As $w=\mathbb{E}[\bar{U}]$, the evaluator breaks even by construction after accounting for wage costs. Given the evaluator's beliefs, his overall expected gross utility in stage 1 in a separating blind audition is

$$
\begin{aligned}
\mathbb{E}\left[V \mid \beta \in \beta_{B}^{H}\right] & =p\left[\operatorname{Pr}\left(h \mid q_{H}\right) \mathbb{E}\left[V \mid q_{H}\right]+\left[1-\operatorname{Pr}\left(h \mid q_{H}\right)\right] \mathbb{E}[\bar{U}]\right]+(1-p)[\mathbb{E}[\bar{U}]], \\
& =p\left[\frac{4+\beta}{4+2 \beta}\left(4-\frac{\beta}{2}\right)+\frac{\beta}{2+\beta}\left(3-\frac{\beta}{2}\right)\right]+(1-p)\left[3-\frac{\beta}{2}\right] .
\end{aligned}
$$

After subtracting wage costs, the evaluator's expected net utility is

$$
\begin{aligned}
\mathbb{E}\left[\Pi_{B} \mid \beta \beta_{B}^{H}\right] & :=\mathbb{E}\left[V \mid \beta \in \beta_{B}^{H}\right]-w, \\
& =p\left[\frac{4+\beta}{4+2 \beta}\left(4-\frac{\beta}{2}-\left(3-\frac{\beta}{2}\right)\right)\right]=p \frac{4+\beta}{4+2 \beta}>0 .
\end{aligned}
$$

Proof of Proposition 4 (i) For $\beta \in \beta_{B}^{L}:=\left[0, \sqrt{p^{2}+16 p}-p-2\right]$, I show that the evaluator's expected net utility in a blind audition is strictly lower than his expected net utility in an informed audition. First, from Lemma 2(iii), it follows that $\frac{5-\sqrt{17}}{2}<\lim _{p \uparrow 1} \beta(p)<\frac{5}{4}$; that is, the highest bias for which a pooling equilibrium can be supported lies in the interval corresponding to $\beta_{I}^{M}$ in an informed audition (see Fig. 2a for an example). Therefore, I need to compare $\mathbb{E}\left[\Pi_{B} \mid \beta \in \beta_{B}^{L}\right]$ with $\mathbb{E}\left[\Pi_{I} \mid \beta \in \beta_{I}^{L}\right]$ and $\mathbb{E}\left[\Pi_{I} \mid \beta \in \beta_{I}^{M}\right]$ to make the above conclusion. From Proposition 1(i) and Proposition 2, 


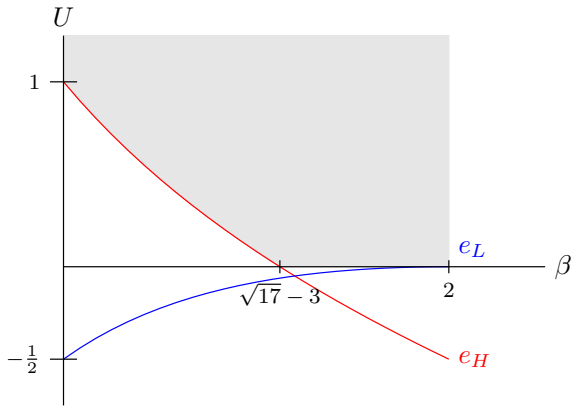

(a) Low-ability applicant.

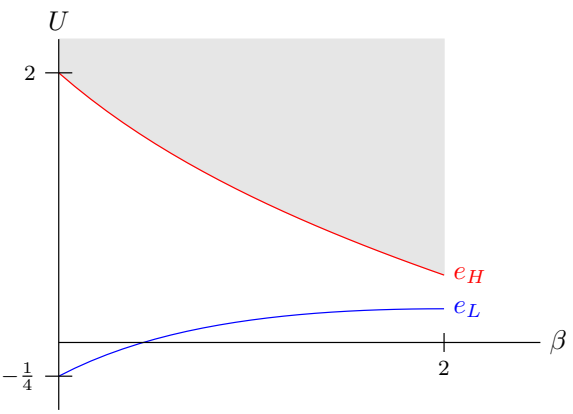

(b) High-ability applicant.

Fig. 12 Effort choices in a separating blind audition

$$
\begin{aligned}
& \mathbb{E}\left[\Pi_{I} \mid \beta \in \beta_{I}^{L}\right]>\mathbb{E}\left[\Pi_{B} \mid \beta \in \beta_{B}^{L}\right], \\
& \quad \Rightarrow \frac{p}{2}\left[\frac{2}{2+\beta}\left(1-\frac{\beta}{2}\right)+\left(1+\frac{\beta}{2}\right)\right]>\frac{2(1+p)+\beta}{4+2 \beta} p,
\end{aligned}
$$

which is true for any $0<p<1$ and $\beta>-2$. From Proposition 1(ii) and Proposition 2 ,

$$
\begin{aligned}
& \mathbb{E}\left[\Pi_{I} \mid \beta \in \beta_{I}^{M}\right]>\mathbb{E}\left[\Pi_{B} \mid \beta \in \beta_{B}^{L}\right], \\
& \quad \Rightarrow \frac{1-p}{2}\left[\frac{\beta}{2+\beta}\left(\frac{\beta}{2}-1\right)\right]+\frac{p}{2}\left[\frac{2}{2+\beta}\left(1-\frac{\beta}{2}\right)+\left(1+\frac{\beta}{2}\right)\right]>\frac{2(1+p)+\beta}{4+2 \beta} p,
\end{aligned}
$$

which is true for any $\frac{1}{5}<p<1$ and $\beta>-2$. By Lemma 2, the lower bound on the prior is more restrictive to support any pooling equilibrium. By assumption, the evaluator's bias is non-negative. Therefore, both inequalities are always satisfied and the evaluator's expected net utility in a blind audition is strictly lower.

(ii) For $\beta \in \beta_{I}^{H} \cap \beta_{B}^{H}=\left(\frac{6}{5}, 2\right)$, I show that the evaluator's net utility in a blind audition is strictly greater than in an informed audition. From Proposition 1(iii) and Proposition 3,

$$
\begin{aligned}
& \mathbb{E}\left[\Pi_{B} \mid \beta \in \beta_{B}^{H}\right]>\mathbb{E}\left[\Pi_{I} \mid \beta \in \beta_{I}^{H}\right], \\
& \quad \Rightarrow p \frac{4+\beta}{4+2 \beta}>\frac{1-p}{2}\left[\frac{\beta}{2+\beta}\left(\frac{\beta}{2}-1\right)\right]+\frac{p}{2}\left[\frac{1}{2+\beta}\left(-\frac{\beta}{2}\right)+\frac{1+\beta}{2+\beta}\left(\frac{\beta}{2}\right)\right],
\end{aligned}
$$

which is true for any $-\frac{1}{8}<p \leq 1$ and $1-\sqrt{8 p+1}<\beta<\sqrt{8 p+1}+1$. By assumption, the lower and upper bound on the prior are more restrictive, and the evaluator's bias lies in the interval $[0,2]$. Therefore, the above inequality is always satisfied.

(iii) For $\beta \in \beta_{I}^{M} \cap \beta_{B}^{H}=\left(\sqrt{17}-3, \frac{6}{5}\right]$, I show that the evaluator's net utility in a blind audition is strictly greater than his expected utility in an informed audition if $0<p<\frac{2-\beta}{2}$. From Proposition 1(ii) and Proposition 3, 


$$
\begin{aligned}
& \mathbb{E}\left[\Pi_{B} \mid \beta \in \beta_{B}^{H}\right]>\mathbb{E}\left[\Pi_{I} \mid \beta \in \beta_{I}^{M}\right], \\
& \quad \Rightarrow p \frac{4+\beta}{4+2 \beta}>\frac{1-p}{2}\left[\frac{\beta}{2+\beta}\left(\frac{\beta}{2}-1\right)\right]+\frac{p}{2}\left[\frac{2}{2+\beta}\left(1-\frac{\beta}{2}\right)+\left(1+\frac{\beta}{2}\right)\right],
\end{aligned}
$$

which is true for any $p \leq 1$ and $0<\beta<2-2 p$.

(iv) For $\beta \in \beta_{I}^{M} \cap \beta_{B}^{H}=\left(\sqrt{17}-3, \frac{6}{5}\right]$, it follows from (iii) that the strict reverse inequality

$$
\mathbb{E}\left[\Pi_{I} \mid \beta \in \beta_{I}^{M}\right]>\mathbb{E}\left[\Pi_{B} \mid \beta \in \beta_{B}^{H}\right]
$$

holds for any $p \leq 1$ and $\beta>2-2 p$.

Proof of Proposition 5 (i) For $\beta \in \beta_{B}^{L}:=\left[0, \sqrt{p^{2}+16 p}-p-2\right]$ and $\frac{1}{3} \leq p<1$, the applicant's expected utility is weakly greater in an blind audition:

$$
\begin{aligned}
& U\left(e_{H}, \eta_{L}\right) \geq U\left(O, \eta_{L}, f\right), \\
& \quad \Rightarrow \frac{2(1+p)+\beta}{4+2 \beta} w-2 \geq 0 .
\end{aligned}
$$

By Lemma 2, the above inequality is the constraint on the range of $\beta$ for which a pooling equilibrium can be supported and, therefore, always satisfied.

(ii) For $\beta \in \beta_{B}^{H}:=(\sqrt{17}-3,2)$, the applicant does not participate in either of the auditions and her expected utility is zero, as shown in Fig. 4 a.

Proof of Proposition 6 (i) First, note that, for $\beta \in[0,2(1-p)]$, the applicant's expected utility is weakly greater in an informed audition:

$$
\begin{aligned}
& U\left(e_{H}, \eta_{H}, f\right) \geq U\left(e_{H}, \eta_{H}\right), \\
& \Rightarrow \frac{2}{2+\beta} \geq \frac{2(1+p)+\beta}{4+2 \beta}, \\
& \Rightarrow \beta \leq 2(1-p) .
\end{aligned}
$$

However, because the upper bound $\beta(p):=\sqrt{p^{2}+16 p}-p-2$, for which a pooling equilibrium can be supported, may be more restrictive than the above inequality, I need to find the range of priors for which either constraint is more restrictive. The indifference condition is

$$
\begin{aligned}
& \sqrt{p^{2}+16 p}-p-2=2(1-p) \\
& \Rightarrow p^{*}=\frac{25-\sqrt{561}}{2} \approx 0.65728 .
\end{aligned}
$$

For priors below $p^{*}, \beta(p)$ is the more restrictive constraint. For priors above $p^{*}$, the upper bound for which a high-ability female prefers an informed audition is given by $\beta \leq 2(1-p)$. 
(ii) For $\beta \in \beta_{B}^{H}:=(\sqrt{17}-3,2)$, the applicant's expected utility is strictly greater in a blind audition, as shown in Fig. $4 \mathrm{~b}$.

Proof of Proposition 7 (i) First, note that, for $\beta \in\left[0, \frac{5-\sqrt{17}}{2}\right)$, the applicant does not participate in an informed audition. If $\beta \geq \frac{5-\sqrt{17}}{2}$, the applicant exerts low effort in an informed audition. Therefore, I need to compare

$$
\begin{aligned}
& U\left(e_{H}, \eta_{L}\right) \geq U\left(e_{L}, \eta_{L}, m\right), \\
& \quad \Rightarrow \frac{2(1+p)+\beta}{4+2 \beta} w-2 \geq \frac{\beta}{2+\beta} w-\frac{1}{2}, \\
& \quad \Rightarrow \beta \leq-\sqrt{p^{2}+2 p+49}+p+7 .
\end{aligned}
$$

However, because the upper bound $\beta(p):=\sqrt{p^{2}+16 p}-p-2$ for which a pooling equilibrium can be supported may be more restrictive than the above inequality, I need to find the range of priors for which either constraint is more restrictive. The indifference condition is

$$
\begin{aligned}
& \sqrt{p^{2}+16 p}-p-2=-\sqrt{p^{2}+2 p+49}+p+7, \\
& \Rightarrow p^{* *}=\frac{31-7 \sqrt{17}}{4} \approx 0.53457
\end{aligned}
$$

For priors below $p^{* *}, \beta(p)$ is the more restrictive constraint. For priors above $p^{* *}$, the upper bound for which a low-ability male prefers a blind audition is given by $\beta \leq-\sqrt{p^{2}+2 p+49}+p+7$.

(ii) For $\beta \in \beta_{B}^{H}:=(\sqrt{17}-3,2)$, the applicant's expected utility is strictly greater in an informed audition, as shown in Fig. 4c.

Proof of Proposition 8 For $\beta \in \beta_{B}^{L}:=\left[0, \sqrt{p^{2}+16 p}-p-2\right]$ and $\frac{1}{3} \leq p<1$, the applicant's expected utility is strictly greater in an informed audition audition:

$$
\begin{gathered}
U\left(e_{H}, \eta_{H}, m\right)>U\left(e_{H}, \eta_{H}\right), \\
\Rightarrow 1>\frac{2(1+p)+\beta}{4+2 \beta}, \\
\Rightarrow \beta>2(p-1) .
\end{gathered}
$$

Given Lemma 2 and the assumption that evaluator's bias is non-negative, the inequality is always satisfied. For $\beta \in \beta_{B}^{H}:=(\sqrt{17}-3,2)$, the applicant's expected utility is also strictly greater in an informed audition, as shown in Fig. 4 d.

Acknowledgements I am grateful to two anonymous referees for excellent suggestions. I thank Willemien Kets, Meg Meyer, Matthew Robertson and Alex Teytelboym for insightful comments. This work was supported by the Economic and Social Research Council [grant number ES/P000649/1]. 
Open Access This article is licensed under a Creative Commons Attribution 4.0 International License, which permits use, sharing, adaptation, distribution and reproduction in any medium or format, as long as you give appropriate credit to the original author(s) and the source, provide a link to the Creative Commons licence, and indicate if changes were made. The images or other third party material in this article are included in the article's Creative Commons licence, unless indicated otherwise in a credit line to the material. If material is not included in the article's Creative Commons licence and your intended use is not permitted by statutory regulation or exceeds the permitted use, you will need to obtain permission directly from the copyright holder. To view a copy of this licence, visit http://creativecommons.org/licen ses/by/4.0/.

\section{References}

Abeles, Hal. (2009). Are musical instrument gender associations changing? Journal of Research in Music Education, 57(2), 127-139.

Adler, Moshe. (1985). Stardom and talent. The American Economic Review, 75(1), 208-212.

Alaref, Jumana, Towfighian, Samira Nikaein, Paez, Gustavo Nicolas \& Audah, Mohammed. (2020). The impact of employer discrimination on female labor market outcomes: Experimental evidence from Tunisia, policy research working paper 9361. Washington: World Bank.

Allmendinger, Jutta \& Richard Hackman, J. (1995). The more, the better? A four-nation study of the inclusion of women in symphony orchestras. Social Forces, 74(2), 423-460.

Antecol, Heather \& Cobb-Clark, Deborah A. (2008). Identity and racial harassment. Journal of Economic Behavior and Organization, 66(3), 529-557.

Anwar, Shamena. (2012). Testing for discrimination: Evidence from the game show street smarts. Journal of Economic Behavior and Organization, 81(1), 268-285.

Arrow, Kenneth. (1973). The theory of discrimination. In O. Ashenfelter \& A. Rees (Eds.), Discrimination in labor markets (pp. 3-33). Princeton: Princeton University Press.

Athey, Susan, Avery, Christopher \& Zemsky, Peter. (2000). Mentoring and diversity. American Economic Review, 90(4), 765-786.

Bagues, Manuel \& Perez-Villadoniga, Maria J. (2012). Do recruiters prefer applicants with similar skills? Evidence from a randomized natural experiment. Journal of Economic Behavior and Organization, 82(1), 12-20.

Becker, Gary S. (1971). The economics of discrimination (2nd ed.). Chicago: University of Chicago Press.

Bertrand, Marianne \& Mullainathan, Sendhil. (2004). Are Emily and Greg more employable than Lakisha and Jamal? A field experiment on labor market discrimination. The American Economic Review, 94(4), 991-1013.

Bertrand, Marianne, Mullainathan, Sendhil, Black, Sandra E., Jensen, Sissel \& Lleras-Muney, Adriana. (2019). Breaking the glass ceiling? The effect of board quotas on female labour market outcomes in Norway. The Review of Economic Studies, 86(1), 191-239.

Cain Miller, Claire. (2016). "Is blind hiring the best hiring?," The New York Times Magazine, 25 February. Available at https://www.nytimes.com/2016/02/28/magazine/is-blind-hiring-the-best-hiring. html. Accessed: 24 February 2019.

Card, David, Kluve, Jochen \& Weber, Andrea. (2010). Active labour market policy evaluations: A metaanalysis*. The Economic Journal, 120(548), F452-F477.

Card, David, Kluve, Jochen \& Weber, Andrea. (2017). What works? A meta analysis of recent active labor market program evaluations. Journal of the European Economic Association, 16(3), 894-931.

Castiglione, Lawrence V. (1985). Performance, practice, and policy considerations. Design For Arts in Education, 1(87), 31-37.

Coate, Stephen \& Loury, Glenn C. (1993). Will affirmative-action policies eliminate negative stereotypes? The American Economic Review, 83(5), 1220-1240.

Conor, Bridget, Gill, Rosalind \& Taylor, Stephanie. (2015). Gender and creative labour. The Sociological Review, 63(S1), 1-22.

Cornell, Bradford \& Welch, Ivo. (1996). Culture, information, and screening discrimination. Journal of Political Economy, 104(3), 542-71. 
Duff, William. (1767). An essay on original genius; and its various modes of exertion in philosophy and the fine arts, particularly in poetry, London: E. and C. Dilly.

Elliott, Charles A. (1995). Race and gender as factors in judgments of musical performance. Bulletin of the Council for Research in Music Education, 127(Winter), 50-56.

Ericsson, K. Anders. (2006). The influence of experience and deliberate practice on the development of superior expert performance. In K. A. Ericsson, N. Charness, P. J. Feltovich, \& R. R. Hoffman (Eds.), The Cambridge handbook of expertise and expert performance (Vol. 38, pp. 683-703). Cambridge: Cambridge University Press.

Ericsson, K. Anders, Krampe, Ralf Th. \& Tesch-Romer, Clemens. (1993). The role of deliberate practice in the acquisition of expert performance. Psychological Review, 3(100), 363-406.

Fryer, Roland \& Jackson, Matthew (2008). A categorical model of cognition and biased decision making. The BE Journal of Theoretical Economics, 8(1), 1-44.

Galenson, David W. (2006). Old masters and young geniuses: The two life cycles of artistic creativity. New Jersey: Princeton University Press.

Galenson, David W. (2009). Old masters and young geniuses: The two life cycles of human creativity. Journal of Applied Economics, 12(1), 1-9.

Gallwey, William T. (1974). The inner game of tennis. New York: Random House.

Gladwell, Malcolm. (2005). Blink: The power of thinking without thinking. New York: Little, Brown and Company.

Glazebrook, Kate. (2019). "What is blind hiring?," https://www.beapplied.com/post/what-is-blind-hiring 22 July 2019. Accessed: 18 November 2019.

Goldin, Claudia \& Rouse, Cecilia. (2000). Orchestrating impartiality: The impact of "blind" auditions on female musicians. The American Economic Review, 90(4), 715-741.

Grossman, Sanford J. (1981). An introduction to the theory of rational expectations under asymmetric information. Review of Economic Studies, 48(4), 541-559.

Günther, Christina, Ekinci, Neslihan A., Schwieren, Christiane \& Strobel, Martin. (2010). Women can't jump?-An experiment on competitive attitudes and stereotype threat. Journal of Economic Behavior and Organization, 75(3), 395-401.

Hart, Philip. (1973). Orpheus in the new world: The symphony orchestras as an american cultural institution-its past, present, and future. New York: W.W. Norton and Company.

Hays, Kate F. \& Brown, Charles H. (2006). You're on! consulting for peak performance. American Psychological Association.

Hellmanzik, Christiane. (2020). Cultural economics. Newcastle upon Tyne: Agenda Publishing.

Hewstone, Miles, Rubin, Mark \& Willis, Hazel. (2002). Intergroup Bias. Annual Review of Psychology, 53(1), 575-604

Holland, Bernard. (1981). "The Fair, New World of Orchestra Auditions," The New York Times, 11 January.

Jensen, Michael C. \& Meckling, William H. (1976). Theory of the firm: Managerial behavior, agency costs and ownership structure. Journal of Financial Economics, 3, 305-360.

Kamakura, Wagner A. \& Schimmel, Carl W. (2013). Uncovering audience preferences for concert features from single-ticket sales with a factor-analytic random-coefficients model. International Journal of Research in Marketing, 30(2), 129-142.

Laffont, Jean-Jacques \& Tirole, Jean. (1986). Using cost observation to regulate firms. Journal of Political Economy, 94(3), 614-641.

Levinson, G. (2017). "Preparing for an orchestral audition: The basics," https://www.thestrad.com/prepa ring-for-an-orchestral-audition-the-basics/6964.article July 2017. Accessed: 22 February 2019.

Makoff-Clark, Annie. (2019). "Is blind recruitment the secret to the perfect hire?," People management, 24 January. Available at https://www.peoplemanagement.co.uk/long-reads/articles/blind-recru itment-secret-perfect-hire. Accessed: 14 November 2019.

Manzoni, John. (2015). "Name-Blind Recruitment - A Commitment to Diversity," 5 November. Available at https://civilservice.blog.gov.uk/2015/11/05/name-blind-recruitment-a-commitment-to-diver sity/. Accessed: 18 November 2019.

McPherson, Gary E. \& Schubert, Emery. (2004). Measuring performance enhancement in music. In A. Williamon (Ed.), Musical excellence: Strategies and techniques to enhance performance (Vol. 4, pp. 61-82). Oxford: Oxford University Press.

Meyer, Margaret A. \& Vickers, John. (1997). Performance comparisons and dynamic incentives. Journal of Political Economy, 105(3), 547-581. 
Milgrom, Paul R. (1981). Good news and bad news: Representation theorems and applications. The Bell Journal of Economics, Autumn, 12(2), 380-391.

Moro, Andrea \& Norman, Peter. (2003). Affirmative action in a competitive economy. Journal of Public Economics, 87(3), 567-594.

Musicians' Union, "Employment Agreements: Negotiated Rates," https://www.musiciansunion.org.uk/ Home/Advice/Playing-Live/Orchestral-Work/Pay-Conditions/Employment-Agreements. Accessed: 23 February 2019.

National Endowment For The Arts. (2009). "Art-goers in their communities: Patterns of civic and social engagement," https:/www.arts.gov/sites/default/files/98.pdf. Accessed: 09 March 2019.

Oberholzer-Gee, Felix. (2008). Nonemployment stigma as rational herding: A field experiment. Journal of Economic Behavior and Organization, 65(1), 30-40.

Page, Lionel \& Page, Katie. (2010). Last shall be first: A field study of biases in sequential performance evaluation on the idol series. Journal of Economic Behavior and Organization, 73(2), 186-198.

Phelps, Edmund S. (1972). The statistical theory of racism and sexism. The American Economic Review, 62(4), 659-661.

Segrest Purkiss, Sharon L., Perrewe, Pamela L., Gillespie, Treena L., Mayes, Bronston T. \& Ferris, Gerald R. (2006). Implicit sources of bias in employment interview judgments and decisions. Organizational Behavior and Human Decision Processes, 101(22), 152-167.

Riach, Peter A. \& Rich, Judith. (2006). An experimental investigation of sexual discrimination in hiring in the english labor market. The BE Journal of Economic Analysis and Policy, 6(2).

Rosen, Sherwin. (1981). The economics of superstars. The American Economic Review, 71(5), 845-58.

Seltzer, George. (1989). Music matters: the performer and the American federation of musicians. New Jersey: Mettuchen Scarecrow Press.

Sergeant, Desmond C. \& Himonides, Evangelos. (2019). Orchestrated sex: The representation of male and female musicians in world-class symphony orchestras. Frontiers in Psychology, 10, 1-18.

Siniscalchi, Marciano \& Veronesi, Pietro. (2020). Self-image bias and lost talent, discussion paper 15621. London: CEPR.

Snower, Dennis J. (1994). The low-skill, bad-job trap. CEPR Discussion Paper Series, Centre for Economic Policy Research, 999, 1-21.

Social Impact of the Arts Project. (2017). "Culture and social wellbeing in New York City: Highlights of a two-year research project,” https://repository.upenn.edu/siap_culture_nyc/2. Accessed: 09 March 2019.

Sowell, Thomas. (2004). Affirmative action around the world: An empirical study, new haven. CT: Yale University Press.

Spence, Michael. (1973). Job market signaling. The Quarterly Journal of Economics, 87(3), 355-374.

Starr, Susan. (1974). The prejudice against women. Music Journal, 32(3), 14-15.

Stronsick, Lisa M., Tuft, Samantha E., Incera, Sara \& McLennan, Conor T. (2018). Masculine harps and feminine horns: Timbre and pitch level influence gender ratings of musical instruments. Psychology of Music, 46(6), 896-912.

Taylor, Curtis R. \& Yildirim, Huseyin. (2011). Subjective performance and the value of blind evaluation. The Review of Economic Studies, 78(2), 762-794.

The Economist. (1996). “All Ears,” The Economist, 30 November, 341 (7994), 89-90; UK 135-136.

Thorngate, Warren, Dawes, Robyn M. \& Foddy, Margaret. (2010). Judging merit. New York: Psychology Press.

Throsby, Charles D. \& Withers, Glenn A. (1979). The economics of the performing arts. London: Edward Arnold Publishers.

Towse, Ruth. (1996). Market value and artists earnings. In A. Klamer (Ed.), The value of culture: On the relationship between economics and arts (Vol. 6, pp. 96-107). Amsterdam: Amsterdam University Press.

Towse, Ruth. (2006). Human capital and artists' labour markets. In V. Ginsburgh \& D. Throsby (Eds.). Handbook of the economics of the arts and culture (Vol. 1, pp. 865-894). Amsterdam: North Holland Elsevier.

Towse, Ruth. (2010). A textbook of cultural economics. Cambridge, UK: Cambridge University Press.

Tsay, Chia-Jung. (2013). Sight over sound in the judgment of music performance. PNAS, 110(36), $14580-14585$.

Tsay, Chia-Jung \& Banaji, Mahzarin R. (2011). Naturals and strivers: Preferences and beliefs about sources of achievement. Journal of Experimental Social Psychology, 47(2), 460-465. 
Universal Music Group. (2011). "Universal music group signs global recording, artist services agreement for new TV music sensation, 'The voice of...,', https://www.universalmusic.com/universal-musicgroup-signs-global-recording-artist-services-agreement-for-new-tv-music-sensation-the-voice-of/. Accessed: 22 February 2019.

U.S. Commission on Civil Rights. (1977). "Statement on affirmative action," Clearinghouse Publication No. 54, pp. 1-12.

Vernos, Isabelle. (2013). Quotas are questionable. Nature, 495, 39.

Publisher's Note Springer Nature remains neutral with regard to jurisdictional claims in published maps and institutional affiliations. 